\title{
FATORES QUE AFETAM O DESENVOLVIMENTO DA COMPOSTAGEM DE RESÍDUOS ORGÂNICOS
}

\section{ISSUES CONCERNING COMPOSTING OF ORGANIC RESIDUES}

\author{
Valente, B.S. ${ }^{1,3}$, E.G. Xavier ${ }^{1}$, T.B.G.A. Morselli², D.S. Jahnke ${ }^{3}$, B. de S. Brum Jr. ${ }^{1}$, \\ B.R. Cabrera ${ }^{3}$, P. de O. Moraes $^{3}$ e D.C.N. Lopes ${ }^{1}$
}

\begin{abstract}
${ }^{1}$ Departamento de Zootecnia. Faculdade de Agronomia Eliseu Maciel. Universidade Federal de Pelotas. Pelotas. RS. Brasil. bsvalente@terra.com.br ${ }^{2}$ Departamento de Solos. Universidade Federal de Pelotas. Pelotas. RS. Brasil.

${ }^{3}$ Núcleo de Estudos em Meio Ambiente (NEMA PEL). Faculdade de Agronomia Eliseu Maciel. Universidade Federal de Pelotas. Pelotas. RS. Brasil.
\end{abstract}

\section{PalaVRAS CHAVES ADICIONAIS}

Humificação. Matéria orgânica. Relação Carbono/ Nitrogênio. Resíduos sólidos.

\section{RESUMO}

A compostagem é um processo de decomposição aeróbia controlada e de estabilização da matéria orgânica em condições que permitem o desenvolvimento de temperaturas termofílicas, resultantes de uma produção calorífica de origem biológica, com obtenção de um produto final estável, sanitizado, rico em compostos húmicos e cuja utilização no solo, não oferece riscos ao meio ambiente. A eficiência do processo de compostagem está diretamente relacionada a fatores que proporcionam condições ótimas para que os microrganismos aeróbios possam se multiplicar e atuar na transformação da matéria orgânica. O conjunto de fatores condicionantes para o bom desenvolvimento de um sistema biologicamente complexo como a compostagem deve ser balizado por uma série de parâmetros, sendo que cada tipo de material a ser compostado exige uma combinação ótima de umidade, aeração, relação $\mathrm{C} / \mathrm{N}, \mathrm{pH}$, granulometria e altura de leira. $\mathrm{A}$ presente revisão objetiva identificar e analisar os principais fatores que, direta ou indiretamente, afetam a atividade microbiológica durante a compostagem.

\section{SUMMARY}

Composting is a process of controlled aerobic decomposition and stabilization of organic matter in conditions allowing the development of

\section{AdDitional KEYWORDS}

Humus. Organic matter. Carbon/Nitrogen ratio. Solid residues.

termophilic temperatures. Such temperatures lead to a stable, sanitized, rich in humus and environmental friendly final product. The efficiency of a composting process is directly related to the factors responsible for an adequate development and multiplication of the aerobic microorganisms acting in the transformation of organic matter. In order to develop an adequate composing process a proper combination of humidity, aeration, $\mathrm{C} / \mathrm{N}$ ratio, $\mathrm{pH}$, granulometry and pile high must be reached. This review aimed to identify and analyze the main factors directly or indirectly affecting microbiological activity during composting process.

\section{INTRODUÇÃO}

O crescimento populacional e o econômico geraram uma forte demanda por alimentos, o que fez com que os diferentes sistemas agropecuários e agroindustriais aumentassem a sua produção, a fim de suprir o grande consumo por parte da população. Além disso, com a globalização do mercado, a possibilidade de exportar os mais variados produtos, tem levado a um crescimento ainda maior destas unidades de produção, principalmente nos países em desenvolvimento (Seiffert, 2000).

Os sistemas produtivos agropecuários 


\section{VALENTE ETAL.}

adotaram métodos intensivos de produção, para tentar suprir essa demanda, que se caracterizam por confinamentos de alta densidade em áreas reduzidas e taxas de crescimento forçadas (Kunz et al., 2008). Números oficiais estimam atualmente que o rebanho brasileiro é composto por aproximadamente 206 milhões de bovinos, 822 milhões de aves, 35 milhões de suínos, 16 milhões de ovinos, 10 milhões de caprinos e 1,6 milhões de bubalinos (ANUALPEC, 2008). Neste contexto, Lucas Junior e Santos (2003) afirmam que o manejo imposto e a intensificação da produção de frangos de corte, favoreceram a geração de maiores quantidades de cama de aviário. De acordo, Miragliotta et al. (2002) afirmam que são alojados de 16 a 20 frangos por metro quadrado, sendo que o volume de cama de aviário disponibilizado para cada frango é de $1,75 \mathrm{~kg}$.

Desta forma, o aumento da produção tem gerado uma grande quantidade de resíduos sólidos e líquidos, que são subprodutos da atividade agropecuária, bem como da agroindustrial, constituindo assim um problema de ordem social, econômica e ambiental. Conforme Fiori et al. (2008), o aumento da produção de resíduos vem provocando impactos ambientais, porque a sua taxa de geração é bem maior que sua taxa de degradação. Contudo, devido à implantação de leis ambientais mais severas, que valorizam o gerenciamento ambiental, tem havido uma conscientização gradual dos efeitos nocivos provocados pelo despejo contínuo de resíduos sólidos e líquidos no meio ambiente. Conjuntamente, o mercado também exige das empresas uma atuação transparente e concreta na preservação dos componentes do meio ambiente, que deve se materializar pela realização de atividades que apresentem um menor impacto ambiental. Desta forma, os sistemas agroindustriais vêm sendo incentivados a reciclar os seus resíduos no sentido de obter maiores rendimentos de seus processos produtivos e, consequentemente, gerar menos resíduos a serem tratados, minimizando assim os custos de disposição final destes resíduos. Desta forma, uma das metas desejadas é a sincronia da liberação de nutrientes com a necessidade das plantas (Bünemann et al., 2004), sendo que para isto deve-se fazer uso de tecnologias que auxiliem na biodegradação destes resíduos orgânicos.

Entretanto, o tratamento e a reciclagem de resíduos orgânicos não representam, necessariamente, uma solução final para os problemas de escassez de alimentos ou do saneamento ambiental, mas podem contribuir significativamente para reduzir os danos causados pela sua disposição desordenada no meio ambiente, além de propiciar a recuperação de solos agrícolas exauridos pela ação de fertilizantes químicos aplicados indevidamente (Lima, 2002).

$\mathrm{Na}$ tentativa de equacionar esse problema, vários métodos de tratamento e disposição de resíduos orgânicos foram e vêm sendo pesquisados em todo o mundo (Vergnox et al., 2009), destacando-se assim a compostagem. Os mesmos autores ressaltam que na França, a compostagem representava $2 \%$ em 1998, sendo que em 2001 chegou a $6 \%$, alcançando em 2004, $16 \%$.

A compostagem é geralmente aplicada a resíduos não fluidos, ou seja, resíduos sólidos provenientes de diversas fontes como resíduos urbanos, agroindustriais e agropecuários, concordando com AmineKhodja et al.(2006). No entanto, os resíduos líquidos também podem ser passíveis de compostagem, sendo que para isso se devem alterar as características físicas destes, através de agentes estruturantes como cama de aviário, casca de arroz, serragem e maravalha. Vergnoux et al. (2009) afirmam que esta tecnologia é utilizada para as mais diversas fontes orgânicas, sendo que para todos os resíduos, o método de compostagem apresenta características e processos similares. Porém, Bidone (2001) afirma que por ser um processo puramente microbiológico, a sua eficiência depende da ação e da 


\section{COMPOSTAGEM DE RESÍDUOS ORGÂNICOS}

interação de microrganismos, os quais são dependentes da ocorrência de condições favoráveis, como a temperatura, a umidade, a aeração, o pH, o tipo de compostos orgânicos existentes, a relação carbono/ nitrogênio $(\mathrm{C} / \mathrm{N})$, a granulometria do material e as dimensões das leiras. De acordo, Kiehl (2004) afirma que a compostagem é um processo controlado de decomposição microbiana, de oxidação e de oxigenação de uma massa heterogênea de matéria orgânica no estado sólido e úmido, compreendendo uma fase inicial rápida mesofílica, que se caracteriza por células microbianas em estado de latência, porém com uma intensa atividade metabólica, apresentando uma elevada síntese de DNA de enzimas (Corrêa, 2003). Posteriormente, ocorre uma fase de bioestabilização, atingindo finalmente a terceira fase, onde ocorre a humificação ou maturação, acompanhada da mineralização de determinados componentes da matéria orgânica, como nitrogênio, fósforo, cálcio e magnésio, que passam da forma orgânica para a inorgânica, ficando disponíveis às plantas (Kiehl, 1985).

Apesar dos estudos existentes sobre o assunto, percebe-se a necessidade de pesquisas aprofundadas sobre a melhoria da eficiência do processo de compostagem, a fim de produzir compostos com de melhor qualidade quanto ao fornecimento de nutrientes as plantas e, também como condicionadores do solo. Neste contexto, Lopez-Real(1994) comenta que, muitas vezes, o insucesso da comercialização do composto é absolutamente dependente da qualidade da matéria-prima básica, seja ela de origem agropecuária, urbana ou industrial. Emerson (2004) complementa, afirmando que a qualidade dos resíduos agrícolas é, quase sempre, mais do que aceitável para a produção de um composto; o problema concentra-se nos de origem urbana e industrial, que geralmente são contaminados por produtos químicos ou constituem-se em materiais grosseiros. Porém, Kiehl (2004) argumenta que fertilizantes orgânicos com uma leve contaminação por metais pesados, inadequados para a adubação de plantas ou de seus produtos comestíveis, podem ser empregados na adubação de plantas ornamentais e de plantas destinadas à contenção de erosão.

Diante dessa situação, o Ministério da Agricultura, Pecuária e Abastecimento MAPA, publicou, em 14 de janeiro de 2004, o decreto no. 4.954, que regulamenta a lei no. 6.894 , de 16 de dezembro de 1980 , e dispõe sobre a inspeção e físcalização da produção, bem como do comércio de fertilizantes orgânicos, corretivos, inoculantes ou biofertilizantes destinados à agricultura (Brasil, 2004). Segundo Beltrane et al.(2006), esse decreto representou um grande salto qualitativo, porque passou a contemplar produtos e matérias-primas, que o decreto anterior, no. 86955 , de 18 de fevereiro de 1982, não reconhecia, além de embasar a publicação das instruções normativas para cada segmento do setor produtivo. Além disso, foi publicada a instrução normativa no. 23 , de 31 de agosto de 2005 , onde são apresentadas as classes e os padrões de qualidade específicos para os fertilizantes orgânicos, que estão diretamente vinculados a origens das matérias-primas utilizadas em sua produção (MAPA, 2005). Neste contexto, o fertilizante orgânico deve apresentar as seguintes garantias para ser comercializado: matéria orgânica total (mínimo de $40 \%$ ), nitrogênio total (mínimo de $1 \%$ ), pH (mínimo de 6,0), relação C/N (máximo de 18/1) e umidade (máximo de 50\%).

A presente revisão objetiva identificar e analisar os principais fatores que, direta ou indiretamente, afetam a atividade microbiológica durante a compostagem e, consequentemente, a qualidade do produto resultante deste processo.

\section{MICRORGANISMOS}

Conforme Miller (1992), o processo de compostagem é marcado por uma contínua mudança das espécies de microrganismos 


\section{VALENTE ETAL.}

envolvidos, devido às modificações nas condições do meio, sendo praticamente impossível identificar todos os presentes. Smith e Paul (1990) ressaltam que o entendimento dos processos microbianos é importante para o conhecimento da ciclagem de nutrientes e da dinâmica da matéria orgânica. Além disso, sabe-se que a intensidade da atividade dos microrganismos decompositores nos processos de compostagem está estritamente relacionada à diversificação e a concentração de nutrientes (Pereira Neto, 2007), sendo que a microbiota do composto determina a taxa de velocidade do processo de compostagem e produz a maior parte das modificações químicas e físicas do material (Mckinley e Vestal, 1985 citado por Tiquia e Tam, 2000; Mondini et al., 2004).

Os principais nutrientes encontrados nos resíduos vegetais e animais estão na forma orgânica e são decompostos em diferentes estágios (Kiehl, 1985), com diferentes intensidades e por diferentes populações de microrganismos, que secretam enzimas e digerem o seu alimento fora da célula (Primavesi, 1981). Para que ocorra a digestão, os microrganismos liberam enzimas hidrolíticas, que retiram porções da matéria orgânica na forma solúvel e de baixo peso molecular, sendo necessária a presença de oxigênio nesta fase, para que a matéria orgânica já absorvida seja metabolizada (Kiehl, 2004).

Segundo Miller (1992), a predominância de determinadas espécies de microrganismos e a sua atividade metabólica determina a fase em que se encontra o processo de compostagem. Corrêa et al. (1982) afirmam que no início da decomposição dos resíduos orgânicos, na fase mesófila, predominam bactérias, que são responsáveis pela quebra inicial da matéria orgânica, promovendo a liberação de calor na massa em compostagem. Nesta fase, ocorre também a atuação de fungos, que são seres heterotróficos, pois utilizam a matéria orgânica sintetizada pelas bactérias e outros microrganismos, como fonte de energia
(Pereira Neto, 2007). Esses microrganismos são produtores de ácidos, que degradam as proteínas, os amidos e os açúcares (Turner, 2002). Com o aumento da temperatura, devido à liberação de calor, ocorre a morte de microrganismos mesófilos (Peixoto, 1988), havendo a multiplicação de actinomicetos, bactérias e fungos termófilos (Riffaldi et al., 1986). Nesta fase, as bactérias degradam os lipídeos e frações de hemicelulose, enquanto que a celulose e a lignina são decompostas pelos actinomicetos e fungos (Kiehl, 1985).

No entanto, Said-Pullicino et al. (2007) e Adams e Frostick (2008) afirmam que a sucessão microbiológica, o envolvimento de comunidades microbiológicas e suas atividades, durante as fases específicas do processo de compostagem ainda são pouco conhecidas.

Em todo o processo de mineralização há um componente de imobilização, uma renovação da matéria orgânica e uma assimilação de nutrientes minerais, que promovem o crescimento e a manutenção da biomassa (Aquino et al., 2005). Além disso, durante todo o processo ocorre produção de calor, com desprendimento de $\mathrm{CO}_{2}$ e de vapor de água (Kiehl, 2004), sendo estas características relacionadas ao metabolismo exotérmico dos microrganismos, à sua respiração e à evaporação de água, que é favorecida pelo aumento da temperatura gerada no interior da massa em compostagem (Zucconi e Bertoldi, 1991).

\section{RELAÇÃOCARBONO/NITROGÊNIO}

A relação $\mathrm{C} / \mathrm{N}$ é um índice utilizado para avaliar os níveis de maturação de substâncias orgânicas e seus efeitos no crescimento microbiológico, já que a atividade dos microrganismos heterotróficos, envolvidos no processo, depende tanto do conteúdo de C para fonte de energia, quanto de $\mathrm{N}$ para síntese de proteínas (Sharma et al., 1997). Desta forma, a relação $\mathrm{C} / \mathrm{N}$ deve ser determinada no material a ser compostado, para efeito de balanço de nutrientes, e também 


\section{COMPOSTAGEM DE RESÍDUOS ORGÂNICOS}

no produto final, para efeito de qualidade do composto (Morrel et al., 1985).

A quantidade de $\mathrm{N}$ exigida por unidade de $\mathrm{C}$ varia com os tipos de microrganismos envolvidos no processo(Peixoto, 1988). Pereira Neto (2007) afirma que o tempo necessário para que se processe a decomposição e a mineralização é, em grande parte, determinado pela concentração de $\mathrm{N}$ da matéria orgânica. Porém, Costa (2005) salienta que a qualidade do $\mathrm{C}$, a ser digerido, também interfere na velocidade e na quantidade de carbono que será transformado em $\mathrm{CO}_{2}$ durante a compostagem.

Diversos pesquisadores afirmam que a relação $\mathrm{C} / \mathrm{N}$ ideal para iniciar o processo de compostagem está entre $25 / 1$ e $35 / 1$ (Zucconi e Bertoldi, 1986; Lopez-Real, 1994; Fong et al., 1999; Kiehl, 2004), uma vez que durante a decomposição os microrganismos absorvem $\mathrm{C}$ e $\mathrm{N}$ da matéria orgânica na relação 30/1, sendo que das 30 partes de $C$ assimiladas, 20 são eliminadas na atmosfera na forma de gás carbônico e 10 são imobilizadas e incorporadas ao protoplasma celular(Gorgati, 2001; Kiehl, 2004).

No entanto, estudos foram realizados utilizando diferentes fontes de dejetos e resíduos da produção animal e vegetal, apresentando como conseqüência uma variação bastante grande na relação $\mathrm{C} / \mathrm{N}$ inicial, desde 5/1 até 513/1. Sabe-se que a disponibilidade de $\mathrm{C}$ é a maior fonte de energia para os microrganismos, porém a sua eficiência não é $100 \%$ e a demanda de C é maior que a do N. Apesar da grande diferença entre as demandas, a carência de $\mathrm{N}$ é limitante no processo, por ser essencial para o crescimento e reprodução dos microrganismos. Quando parte do C disponível é de difícil degradação, como a celulose, a lignina e a hemicelulose, é aconselhável uma relação $\mathrm{C} / \mathrm{N}$ inicial maior, pois o $\mathrm{C}$ biodisponível é inferior ao $\mathrm{C}$ total. Apesar dos valores sugeridos pelos pesquisadores para a relação $\mathrm{C} / \mathrm{N}$ ótima na compostagem, constata-se que não poderá ser um valor absoluto, mas sim, que deve variar com as características do material a compostar. De acordo, Imbar et al. (1993) e Silva (2005) afirmam que além da natureza do material, a condução da compostagem também afeta de maneira significativa a concentração de $\mathrm{C}$ total durante o processo de compostagem.

Pesquisando a compostagem de esterco de suínos e palha de arroz, Zhu (2007) verificou que a relação inicial de $20 / 1$ foi benéfica ao processo de compostagem. De modo semelhante, Benito et al. (2006) trabalhando com compostagem de resíduos de podas, verificaram que a relação $\mathrm{C} / \mathrm{N}$ variou entre 22/1 e 48/1. Entretanto, Gorgati (2001) pesquisando a compostagem com a fração orgânica do lixo urbano do município de São Lourenço da Serra/SP, verificou que independente das relações $\mathrm{C} / \mathrm{N}$ iniciais dos materiais coletados na primavera, no verão, no outono e no inverno serem, respectivamente, 10/1, 13/1, 17/1 e 14/1, a relação C/N média foi de 11/1 para as leiras descobertas e de 6/1 para as que permaneceram cobertas, indicando uma estabilização do material orgânico ao longo do período. A baixa relação $C / N(6 / 1)$ pode ter sido influenciada pela condução da compostagem, já que a origem, bem como o tipo de material utilizado na confecção das leiras foi o mesmo, diferindo apenas no fato de não serem cobertas. Possivelmente, a incidência de chuvas durante período estudado, tenha proporcionado uma maior produção de chorume, o que aumentou a lixiviação de nutrientes, diminuindo assim a sua concentração no produto final.

Durante o processo de compostagem verifica-se, portanto, uma redução da relação $\mathrm{C} / \mathrm{N}$ em decorrência da oxidação da matéria orgânica pelos microrganismos, que liberam $\mathrm{CO}_{2}$ através da sua respiração (Zhang e He, 2006), diminuindo assim a concentração de C. Neste contexto, Loureiro et al. (2007) avaliaram a compostagem de resíduos domiciliares com e sem adição de esterco bovino e observaram uma redução no teor de C total, ao longo de 27 dias de 


\section{VALENTE ETAL.}

compostagem. Utilizando um período maior de compostagem, de 180 dias, Costa et al. (2006) trabalharam com carcaças avícolas e cama de aviário, e observaram uma redução no teor de $\mathrm{C}$ total tanto no primeiro como no segundo estágio. Porém, Imbar et al. (1990) observaram que nos primeiros 60 dias de compostagem de resíduos das indústrias de alimentos, a relação $\mathrm{C} / \mathrm{N}$ diminuiu rapidamente de 27/1 para 10/1. Lima (2006), estudando a compostagem da mistura de diversos materiais como o bagaço de cana, a cinza de bagaço de cana e o esterco de galinhas poedeiras em recipientes perfurados lateralmente, com capacidade de 601, com e sem adição de minerais, verificou que ao final de 120 dias de compostagem, os tratamentos apresentaram relação $\mathrm{C} / \mathrm{N}$ variando entre 11/1 e 14/1.

Em um tempo maior de compostagem, Corrêa (1998) avaliou diferentes tipos de camas na criação de suínos, como casca de arroz, maravalha, sabugo de milho e serragem, e verificou que no alojamento dos animais, no primeiro lote, os materiais apresentaram, respectivamente, os seguintes valores para a relação C/N: 85/1; 513/1;87/1 e 179/1, sendo que ao final de três lotes criados sobre as camas, os valores reduziram para $14 / 1 ; 15 / 1 ; 12 / 1$ e 20/1, respectivamente.

Pode-se constatar que apesar dos pesquisadores concordarem que a concentração de carbono diminui ao longo do período de compostagem, o tempo para que ocorra a estabilização ou a maturação dos resíduos orgânicos, está diretamente relacionado à relação $\mathrm{C} / \mathrm{N}$ inicial dos materiais utilizados como substratos. Ainda, baseado nos resultados dos experimentos desenvolvidos, pode-se dizer que para alcançar uma relação $\mathrm{C} / \mathrm{N}$ adequada é necessário misturar diferentes resíduos orgânicos. Dai Prá (2006) trabalhando na transformação de dejetos líquidos de suínos em sólidos, através da incorporação á diferentes materiais celulósicos, que sofreram compostagem por um período de 105 dias, observou que à medida que os dejetos foram adicionados aos substratos maravalha (212/ 1) e serragem (217/1), houve uma significativa redução na relação $\mathrm{C} / \mathrm{N}$ em ambos os tratamentos, para $21 / 1$ e $20 / 1$, respectivamente. Entretanto, o mesmo autor observou que os dejetos que foram adicionados ao substrato cama de aviário (5/1), apresentaram um aumento da relação $\mathrm{C} / \mathrm{N}(15 / 1)$.

Apesar da cama de aviário ter sido constituída de maravalha, que apresenta uma alta relação $\mathrm{C} / \mathrm{N}$, a presença de excretas das aves contribuiu para a diminuição da relação $\mathrm{C} / \mathrm{N}$ do substrato. Percebe-se ainda que os dejetos que formam incorporados ao substrato podem ter acarretado uma redução ainda maior da relação $\mathrm{C} / \mathrm{N}$, o que possivelmente deve ter provocado uma maior volatilização de amônia. Kelleher et al. (2002) ressaltam que a baixa relação $\mathrm{C} / \mathrm{N}$ dos resíduos orgânicos provenientes da avicultura, contribuem para a maior perda de amônia. De outra forma, Zhu (2007) afirma que valores mais elevados de relação C/ $\mathrm{N}$ significam que não há $\mathrm{N}$ suficiente para um ótimo crescimento das populações microbianas, havendo consumo de $\mathrm{N}$ pelos microrganismos, prejudicando assim a velocidade de decomposição dos resíduos orgânicos, que será reduzida.

Contrariando os autores, Chanyasak e Kubota (1981) realizaram estudos sobre as mudanças na relação $\mathrm{C} / \mathrm{N}$ de diferentes resíduos e constataram que os valores permaneceram constantes entre $5 / 1$ e $6 / 1$, sem importar o tipo de material utilizado na compostagem. Entretanto, sendo estes valores próximos à relação $\mathrm{C} / \mathrm{N}$ da composição celular dos microrganismos, a relação pode ter sido mascarada pela presença de compostos orgânicos de composição similar que não tenham sido degradados (Chanyasak et al., 1982), como fibras de celulose e lignina (Rodrigues et al., 2006). Os microrganismos heterotróficos utilizam preferencialmente os carboidratos como fonte de $\mathrm{C}$, devido à lenta biodegradação da lignina, que se apresenta bastante resistente ao ataque enzimático, reduzindo assim o 


\section{COMPOSTAGEM DE RESÍDUOS ORGÂNICOS}

teor de celulose e hemicelulose nos primeiros 90 dias de decomposição (Dinel et al., 1991).

\section{UMIDADE}

A umidade é indispensável para a atividade metabólica e fisiológica dos microrganismos, sendo que a considerada ideal para a compostagem varia entre 50 e $60 \%$ (Stentiford, 1996 citado por Tiquia et al., 1998a; Rodrigues et al., 2006). Richard et al. (2002) afirmam que materiais com $30 \%$ de umidade inibem a atividade microbiana, sendo que um meio com umidade acima de $65 \%$ proporciona uma decomposição lenta, condições de anaerobiose e lixiviação de nutrientes. O excesso de umidade reduz a penetração de oxigênio na leira, uma vez que a matéria orgânica decomposta é hidrófila e as moléculas de água se aderem fortemente à superfície das partículas, saturando os seus micro e macroporos (Ecochem, 2004), afetando as propriedades físicas e químicas do composto (Tiquia et al., 1998b). A umidade interfere também indiretamente na temperatura do processo de compostagem, que é uma conseqüência da atividade metabólica dos microrganismos, que ocorre na fase aquosa. De acordo, Margesin et al. (2006) estudaram a atividade biológica durante a compostagem de lodo de esgoto e verificaram que a redução do teor de umidade prejudicou a atividade metabólica dos microrganismos, afetando assim diretamente a temperatura. Vários estudos foram realizados objetivando obter o melhor nível de umidade que pudesse afetar positivamente o desenvolvimento dos microrganismos e, conseqüentemente, a temperatura do composto. Nos experimentos, a umidade testada variou de 40 a $70 \%$.

Barrington et al. (2003) estudaram o efeito da aeração passiva e ativa na compostagem de dejetos de suínos com três substratos diferentes (maravalha, palha e feno) e com níveis de $60 \%, 65 \%$ e $70 \%$ de umidade, concluindo que a umidade é um fator determinante nos padrões de temperatura alcançados durante a compostagem, principalmente no caso dos substratos maravalha e palha. Verificaram ainda que, no caso da maravalha, a umidade de $65 \%$ influenciou no aumento da temperatura nos regimes de aeração adotados. Já no caso da palha, a umidade de $70 \%$ proporcionou as temperaturas mais altas para os regimes de aeração. No entanto, os mesmos pesquisadores concluíram que o fator umidade teve efeito sob a temperatura apenas entre o $2^{\circ}$ e o $6^{\circ}$ dia. Este fato nos leva a acreditar que possivelmente outros fatores estivessem influenciando o aumento da temperatura como a concentração de nutrientes, as dimensões das leiras e a capacidade das partículas de resistir à compactação.

Em outro experimento, realizado por Tiquia et al. (1996) foi avaliado o efeito de três níveis de umidade $(50,60$ e $70 \%)$ sobre a atividade microbiana em compostagem de cama de suínos. Os resultados indicaram um efeito significativo da umidade sobre a atividade microbiana e, conseqüentemente, sobre a temperatura da massa em compostagem. Os pesquisadores observaram que o teor de umidade entre 50 e $60 \%$ permitiu uma atividade microbiana significativamente maior do que níveis de umidade na ordem de $70 \%$, devido às trocas gasosas e a penetração do oxigênio na massa em compostagem. Porém, Sellami et al. (2008) estudaram a compostagem da mistura de resíduos da produção de azeite de oliva, de excretas de aves e de casca de gergelim e constataram que o teor de umidade na faixa de 50 a $700 \mathrm{C}$ provocou um aumento da degradação da matéria orgânica. Já, Sivakumar et al.(2007) estudaram a compostagem de carcaças de frangos, de excretas de frangos e de palha, e verificaram que o teor de umidade entre 40 e $65 \%$ estimulou a atividade microbiana.

A umidade tem, portanto, juntamente com a aeração, o pH, a relação $\mathrm{C} / \mathrm{N}$, a granulometria do material e as dimensões das leiras, um efeito direto sobre o desenvolvimento de microrganismos e indireto sobre a temperatura do processo de 


\section{VALENTE ETAL.}

compostagem, sendo que a considerada ótima varia em função do tipo de material a ser compostado e do material celulósico utilizado. Conforme Peixoto (1988), a eficiência do processo de compostagem baseia-se na interdependência e no interrelacionamento desses fatores.

\section{AERAÇÃO}

A aeração é o fator mais importante a ser considerado no processo de decomposição da matéria orgânica (Peixoto, 1988), sendo classificado como o principal mecanismo capaz de evitar altos índices de temperatura durante o processo de compostagem, de aumentar a velocidade de oxidação, de diminuir a liberação de odores e reduzir o excesso de umidade de um material em decomposição (Pereira Neto, 1994; Kiehl, 2004).

De acordo com a disponibilidade de oxigênio, a compostagem pode ser classificada como aeróbia ou anaeróbia. A compostagem aeróbia corresponde à decomposição dos substratos orgânicos na presença de oxigênio, sendo que os principais produtos do metabolismo biológico são $\mathrm{CO}_{2}, \mathrm{H}_{2} \mathrm{O}$ e energia. De outra forma, na compostagem anaeróbia, a decomposição dos substratos orgânicos ocorre na ausência de oxigênio, produzindo $\mathrm{CH}_{4}$ e $\mathrm{CO}_{2}$, além de produtos intermediários, como ácidos orgânicos de baixo peso molecular (Pereira Neto, 1996; Kiehl, 2004). Entretanto, quando se busca a compostagem como tratamento de resíduos orgânicos, procura-se oferecer um ambiente aeróbio para que os microrganismos se desenvolvam, diminuindo assim a emissão de odores e de gases causadores do efeito estufa como o metano e o óxido nitroso. Além disso, diferentemente do que ocorre na compostagem anaeróbia, a presença de oxigênio na massa faz com que ocorra uma decomposição mais rápida da matéria orgânica. Desta forma, Costa (2005) afirmam que a intensificação dos revolvimentos nas leiras diminui o tempo de compostagem.

As leiras podem ser aeradas por meio de revolvimentos manuais ou mecânicos, fazendo com que as camadas externas se misturem às internas, que estão em decomposição mais adiantada (Kiehl, 1985; Pereira Neto, 1994; Silva et al., 2001). Richard et al. (2002) afirmam que as concentrações de oxigênio acima de $10 \%$ são consideradas ótimas para a manutenção da compostagem em condições de aerobiose.

Entretanto, a aeração deve ser muito bem controlada, uma vez que um suprimento excessivo de ar pode fazer com que a perda de calor seja mais intensa do que a produção de calor microbiano (Lau et al., 1992). Além disso, Kader et al. (2007) afirmam que a aeração excessiva pode aumentar a emissão de gases poluentes como a amônia e o óxido nitroso. Os mesmos autores, trabalhando com a compostagem de esterco bovino e de esterco de peru, em células, que receberam diferentes tipos de tratamentos (compactação, revolvimento e adição de água), verificaram que a redução de oxigênio entre 20 a $60 \%$ nos tratamentos compactação e adição de água, reduziu a emissão de amônia e óxido nitroso, que ficou entre 30 e $70 \%$.

Um experimento foi realizado com o objetivo de testar diferentes freqüências de aeração na compostagem de cama, oriunda do sistema de criação de suínos, com umidade corrigida para $50 \%$ no início do período experimental (Tiquia et al., 1997). Os pesquisadores verificaram que o revolvimento da pilha a cada 2 ou 4 dias é mais adequado ao processo de compostagem em comparação ao revolvimento realizado a cada 7 dias. Zhu et al. (2004) avaliaram a influência de três sistemas de aeração (ativa, passiva e natural) nas características físico-químicas de compostagem da mistura de dejetos sólidos de suínos e casca de arroz. Os resultados indicaram que para a variável temperatura, houve um aumento significativo, quando foi utilizada a aeração forçada. Para as demais características como, o pH, o C, o $\mathrm{N}$, a relação $\mathrm{C} / \mathrm{N}$ e a matéria orgânica, não houve diferença significativa entre os três sistemas. No entanto, Barrington et al. 


\section{COMPOSTAGEM DE RESÍDUOS ORGÂNICOS}

(2003) estudaram o efeito da aeração passiva e ativa na compostagem de dejeto de suíno com três substratos diferentes (maravalha, palha e feno) em umidades de 60,65 e $70 \%$ e concluíram que a aeração passiva foi tão eficiente quanto a aeração ativa em manter temperaturas estabilizadas em $55^{\circ} \mathrm{C}$ para todos os substratos utilizados e para as três umidades testadas.

Considerando-se os dados encontrados nos trabalhos realizados por Tiquia et al. (1997), Zhu et al. (2004) e Barrington et al. (2003), o efeito da aeração parece ser limitado. Neste sentido, alguns autores afirmaram que aproximadamente uma hora após, o nível de oxigênio da leira se aproxima de zero (Tardy e Beck, 1996; Fernandes e Silva, 1999). Neste sentido, Pereira Neto (2007) comenta que muitas vezes o oxigênio no interior das leiras é tão baixo, que alguns aparelhos não conseguem detectá-lo. Kader et al. (2007) trabalharam com a compostagem de esterco bovino em leiras com e sem revolvimentos e, verificaram que a leira revolvida apresentou durante o primeiro e segundo dia, temperaturas maiores do que as leiras não revolvidas. Porém, no terceiro dia de compostagem, a temperatura máxima no centro das pilhas foi similar para ambos os tratamentos, 75 e $78^{\circ} \mathrm{C}$, respectivamente. Também, Costa (2005) testando o efeito da realização ou não de aeração por meio de exaustores eólicos, durante a compostagem de carcaças de aves realizada em células, concluíram que houve semelhança no comportamento da temperatura tanto no sistema com aeração como no sem aeração.

Baseado nos estudos acima, se pode dizer que, a atividade microbiana no interior da massa em compostagem, ocorre na presença de quantidades muito reduzidas de oxigênio e que a ausência de revolvimentos não é um fator prejudicial para o desenvolvimento do processo. No entanto, ele se faz necessário no caso da compostagem de resíduos líquidos, sendo utilizado para acelerar a evaporação do excedente de umidade. Dai Prá (2006) trabalhando na transformação de dejetos líquidos em sólidos por meio da compostagem, observou um aumento da temperatura da massa em compostagem, após o revolvimento a cada três dias, em todos os tratamentos avaliados (cama de aviário, serragem e maravalha).

Conforme alguns pesquisadores, os revolvimentos deveriam ser realizados de acordo com o teor de oxigênio no interior da leira (Kiehl, 1985; Fernandes e Silva, 1999; Komilis e Ham, 2003), porém, devido à dificuldade de se determinar a concentração de oxigênio no centro da leira, o momento adequado para se fazer o revolvimento é decidido em função de outros fatores, como a temperatura, a umidade e o intervalo de dias. Sellami et al. (2008) trabalhando com a compostagem da mistura de resíduos da produção de azeite de oliva, excretas de aves e casca de gergelim, em leiras estáticas arejadas, tomaram como parâmetro para a freqüência dos revolvimentos, a temperatura interna de $55^{\circ} \mathrm{C}$. Por sua vez, Gorgati (2001) estudando a compostagem da fração orgânica do lixo urbano do município de São Lourenço do Sul/SP, escolheu a temperatura e a umidade do material enleirado como referencial para realizar os revolvimentos. De outra forma, Benito et al. (2006) compostando resíduos de plantas, realizaram os revolvimentos quando a temperatura excedeu os $80^{\circ} \mathrm{C}$ ou então, quando a taxa de oxigênio saturado, no interior da leira, fosse inferior a $82 \%$. A temperatura parece ser um dos parâmetros mais utilizados pelos pesquisadores para determinar a frequência dos revolvimentos, já que expressa a atividade dos microrganismos no interior da massa.

\section{$\mathrm{PH}$}

Os principais materiais de origem orgânica, utilizados como matéria-prima na compostagem, são de natureza ácida, como sucos vegetais, sangue, urina, fezes, dentre outros. Dessa forma, em geral, uma leira de matéria orgânica tem inicialmente reação 


\section{VALENTE ETAL.}

ácida. Ainda, no início da decomposição ocorre à formação de ácidos orgânicos e a incorporação de carbono orgânico ao protoplasma celular microbiano, o que torna o meio mais ácido em relação ao inicial. Esta fase caracteriza-se pela presença de intensa atividade de microrganismos mesófilos, que elevam a temperatura da massa em compostagem à aproximadamente 40- $45^{\circ} \mathrm{C}$ e, em decorrência de sua atividade, liberam também C orgânico na forma de $\mathrm{CO}_{2}$ para a atmosfera (Tuomela et al., 2000). Ainda, os ácidos orgânicos e os traços de ácidos minerais que se formam reagem com bases liberadas da matéria orgânica, gerando compostos de reação alcalina (Sharma et al., 1997; Jahnel et al., 1999; Dai Prá, 2006). Ocorre também à formação de ácidos húmicos, que também reagem com os elementos químicos básicos, formando humatos alcalinos. Desta forma, o $\mathrm{pH}$ do composto aumenta a medida que o processo se desenvolve, atingindo muitas vezes, níveis superiores a 8,0 (Kiehl, 2004).

A faixa de $\mathrm{pH}$ considerada ótima para o desenvolvimento dos microrganismos responsáveis pela compostagem situa-se entre 5,5 e 8,5, uma vez que a maioria das enzimas encontram-se ativas nesta faixa de pH (Rodrigues et al., 2006). Porém, Pereira Neto (2007) afirma que a compostagem pode ser desenvolvida em uma faixa de $\mathrm{pH}$ entre 4,5 e 9,5 , sendo que os valores extremos são automaticamente regulados pelos microrganismos, por meio da degradação dos compostos, que produzem subprodutos ácidos ou básicos, conforme a necessidade do meio. No entanto, Primavesi (1981) afirma que as alterações do $\mathrm{pH}$ podem ativar ou quase inativar as enzimas presentes nos microrganismos.

Apesar da contradição apontada por Rodrigues et al. (2006) e Pereira Neto (2007), quanto aos valores ótimos de $\mathrm{pH}$, sabe-se que não há problemas em se utilizar substratos que apresentem baixo $\mathrm{pH}$, já que durante a compostagem ocorrerá inúmeras reações químicas que irão regular esta acidez, gerando um produto final com $\mathrm{pH}$ entre 7,0 e 8,5. Neste sentido, Isoldi (1998) afirma que as reações do tipo ácido-base e de óxido-redução são de extrema importância na compostagem.

Pesquisa realizada com a compostagem de lixo urbano demonstrou que no início do processo a massa em compostagem apresentou-se ácida ( $\mathrm{pH}$ em torno de 5,0) e, após cerca de 50 dias, atingiu valores próximos a 8,5 (Jahnel et al., 2008). Em experimento, visando estudar a compostagem de dejetos sólidos de suínos misturados com serragem, Zhang e He (2006) demonstraram que inicialmente o valor do $\mathrm{pH}$ encontra-se levemente ácido e, ao longo do processo torna-se alcalino, sendo que ao final tornase novamente ácido, porém em valores próximos da neutralidade, sendo um importante indicativo de estabilização da biomassa. Entretanto, Deon et al. (2007) estudaram a compostagem da mistura de resíduos alimentares com restos de jardim e concluíram que o $\mathrm{pH}$ do composto, ao longo do período, permaneceu constante, em torno de 7,8 .

Baseado nos resultados dos experimentos pode-se dizer que as transformações químicas e físicas, que são realizadas pela atividade microbiana, são diretamente dependentes das características físico-químicas da mistura dos substratos utilizados no processo. Barrington et al. (2002) e Richard et al. (2002) afirmam que o excesso de carbono em determinados resíduos orgânicos, pode propiciar condições ácidas na massa de compostagem, já que o $\mathrm{CO} 2$ liberado é muito solúvel. Leita e De Nobili (1991) e Imbar et al. (1993) afirmam que a condução da compostagem também afeta fortemente a concentração do carbono solúvel em água. De outra forma, Komilis e Tziouvaras (2009) afirmam que a solubilidade do $\mathrm{CO}_{2}$ na água é diretamente dependente do $\mathrm{pH}$, aumentando quando o $\mathrm{pH}$ se eleva. Neste sentido, Sundberg et al. (2004) verificaram que em $\mathrm{pH}$ acima de 6,5 , a solubilidade do $\mathrm{CO}_{2}$ foi maior. 


\section{COMPOSTAGEM DE RESÍDUOS ORGÂNICOS}

De forma contrária, Abid e Sayadi (2006) estudaram a compostagem da mistura de resíduos da agricultura com diferentes níveis de excretas de aves e águas residuárias da indústria de azeite. Verificaram que a solubilidade do carbono orgânico aumentou nos primeiros 20 dias de compostagem, diminuindo gradualmente até o final do processo, sendo independente do $\mathrm{pH}$, que apresentou variações entre 7,2 e 8,3. O autor atribuiu este fato a acumulação de compostos orgânicos solúveis presentes na água residuária da indústria de azeite. Conforme Eggen e Vethe (2001), a fração de carbono solúvel demonstra ser um parâmetro químico que se correlaciona positivamente com a taxa de respiração, em vários tipos de compostos. No entanto, Abid e Sayadi (2006) constataram que a atividade microbiológica diminuiu com o aumento da taxa de carbono solúvel em água devido ao aumento da solubilidade de fenóis.

Com base nos estudos, pode-se perceber que a concentração de carbono solúvel em água, está relacionada ao equilíbrio entre várias reações que aumentam ou diminuem a concentração de matéria orgânica dissolvida durante a compostagem. SaidPullicino et al. (2007) afirmam que o aumento da concentração de carbono orgânico solúvel em água, ocorre devido a solubilização dos componentes lábeis da matéria orgânica e também em decorrência de uma nova síntese bioquímica de componentes com maior peso molecular, enquanto que, a sua redução depende da mineralização contínua dos componentes orgânicos solúveis, da repolimerização e também da condensação de substâncias orgânicas complexas que apresentam uma menor solubilidade em água.

Segundo Isoldi (1998) e Baird (2002), o equilíbrio ácido-base permite entender o comportamento do $\mathrm{pH}$. Sabe-se que o $\mathrm{CO}_{2}$, que provém da decomposição da matéria orgânica e da respiração microbiana, pode se apresentar sob diferentes formas químicas. Neste sentido, Nascimento (1996) e
Baird(2002) afirmam que o sistema carbônico, compreende as moléculas de $\mathrm{CO}_{2}$, bicarbonato $\left(\mathrm{HCO}_{3}^{-}\right)$e carbonato $\left(\mathrm{CO}_{3}^{-}\right)$e que se apresentam em equilíbrio em função do $\mathrm{pH}$. Conforme Ramjeawon (2001), a propriedade de tamponamento do $\mathrm{pH}$, vem naturalmente da produção do $\mathrm{CO} 2$ e da liberação de íons carregados positivamente, da decomposição de proteínas e outros substratos. Neste sentido, Wetzel (1983) afirma que quando o $\mathrm{CO}_{2}$ reage com a umidade presente no substrato, uma pequena proporção (menos que $1 \%$ ) é hidratada para formar ácido carbônico $\left(\mathrm{H}_{2} \mathrm{CO}_{3}\right)$. Uma parte deste ácido se dissocia e forma $\mathrm{HCO}_{3}$-, bem como íons de hidrogênio, o que provoca a diminuição do $\mathrm{pH}$ do substrato. Em sentido contrário, esta reação resulta em outro próton. Deste modo, pode-se concluir que se o $\mathrm{pH}$ aumenta, como resultado da absorção do $\mathrm{CO}_{2}$ pelos microrganismos, o equilíbrio move-se para produção de $\mathrm{CO}_{3}-$. Por outro lado, em valores mais baixos de $\mathrm{pH}$, que são resultantes de processos de respiração e da decomposição da matéria orgânica, as formas $\mathrm{CO}_{2} \mathrm{eH}_{2} \mathrm{CO}_{3}$ predominam.

Por outro lado, as variações enzimáticas, que ocorrem durante o processo, são diretamente dependentes da atividade microbiana presente em cada fase. Embora, Carneiro (1995) afirme que em pH ácidos há uma redução considerável da população de bactérias e actinomicetos, Tsai et al. (1992) afirmam que há uma grande heterogeneidade de microrganismos envolvidos na degradação dos resíduos orgânicos durante a compostagem. Assim, de um modo geral, pode-se dizer que as variações enzimáticas são uma característica do processo, devido à colonização por diferentes microrganismos, que determinam a fase em que se encontra a compostagem.

O pH alcalino no início da compostagem parece prejudicar o processo de compostagem. De acordo, Gorgati (2001) afirma que o pH alcalino no início do processo de compostagem acarreta perdas de $\mathrm{N}$ pela volatilização de amônia. Entretanto, Victoria et al. (1992) afirmam que a hidrólise da amônia $\left(\mathrm{NH}_{3}\right)$ 


\section{VALENTE ETAL.}

acarreta um aumento do $\mathrm{pH}$, devido à produção de hidroxilas, transformando-se em amônio $\left(\mathrm{NH}_{4}+\right)$. Da mesma forma, o pHé responsável pelo equilíbrio entre o amônio $\left(\mathrm{NH}_{4}+\right)$ e a amônia $\left(\mathrm{NH}_{3}\right)$, sendo que quando a amônia é perdida por volatilização, ocorre uma dissociação do íon $\mathrm{NH}_{4}+$, uma vez que a oxidação do amônio $\left(\mathrm{NH}_{4}+\right)$ a nitrato $\left(\mathrm{NO}_{3}-\right)$ libera $2 \mathrm{H}+$, reduzindo o $\mathrm{pH}$ do meio (Moreira e Siqueira, 2002; Mackenzie et al., 2006). De acordo, Lima (2006) estudou a compostagem da mistura de diversos materiais, como o bagaço de cana, a cinza de bagaço de cana e o esterco de galinha poedeira em recipientes perfurados lateralmente, com capacidade de 601 e verificou que o pH manteve-se ácido durante todo o processo, devido ao teor elevado de $\mathrm{N}$ presente nos substratos compostados.

Entretanto, Valente (2008) estudando a compostagem da mistura de cortes nobres de frangos de corte e cama de aviário, observou que o $\mathrm{pH}$ manteve-se alcalino durante os 120 dias do primeiro estágio de compostagem, que foi realizado em células, com temperaturas médias em torno de $55^{\circ} \mathrm{C}$. Porém, também verificou uma elevação significativa do $\mathrm{pH}$ entre a fase final do primeiro estágio $(8,62)$ e a fase inicial do segundo estágio $(9,66)$, que foi realizado em leiras $(\mathrm{p}<0,05)$, e ainda uma redução significativa ao final do processo de compostagem $(7,68)$. A redução do $\mathrm{pH}$, possivelmente tenha sido favorecida pela adição de água e pelos revolvimentos a cada 18 dias, que proporcionou uma maior elevação da temperatura $\left(65^{\circ} \mathrm{C}\right)$, favorecendo a volatilização da amônia e a oxidação do amônio a nitrato, concordando com Moreira e Siqueira (2002) e ainda com Sanchez-Monedero et al. (2001) que afirmam que o amônio produzido é oxidado a nitrato $\left(\mathrm{NO}_{3}-\right)$, quando a temperatura da mistura está acima dos $40^{\circ} \mathrm{C}$ e também quando há condições favoráveis de aeração.

Sundberg et al. (2004) afirmaram que durante a fase inicial da compostagem de resíduos orgânicos domiciliares, as tem- peraturas próximas a $46^{\circ} \mathrm{C}$ e $\mathrm{pH}$ abaixo de 6,0 inibem a atividade de microrganismos. Pode-se dizer que possivelmente a inibição da atividade microbiana tenha sido em decorrência da transição da fase mesófila $\left(40-45^{\circ} \mathrm{C}\right)$ para a termófila, onde naturalmente ocorre uma estagnação da atividade microbiana devido à morte de microrganismos mesófilos e a colonização da massa pelos microrganismos termófilos. Ou, ainda, pode ter ocorrido uma diminuição de $\mathrm{O}_{2}$ no interior da massa, prejudicando assim a metabolização da matéria orgânica já absorvida pelos microrganismos. Alguns autores têm notado um declínio na atividade microbiológica na transição da fase mesófila para a termólfila durante a compostagem de resíduos alimentares ou outros resíduos ácidos (Haug, 1993; Reinhardt, 2002).

\section{TEMPERATURA}

A temperatura é considerada por muitos pesquisadores como o mais importante indicador da eficiência do processo de compostagem, estando intimamente relacionada com a atividade metabólica dos microrganismos, a qual é diretamente afetada pela taxa de aeração (Pereira Neto, 1988; Imbeah, 1998 citado por Li et al., 2008). Tiquia et al. (1997) estudando a compostagem da mistura de dejetos de suínos e serragem concluíram que a aferição da temperatura é um parâmetro que pode indicar a taxa de decomposição e a maturidade do composto, sendo considerado maduro, quando a temperatura atingir valores próximos a temperatura ambiente.

Todavia, considerando que o desenvolvimento da temperatura, durante a compostagem, é afetado por fatores como a umidade do substrato, a disponibilidade de nutrientes, bem como o tamanho das leiras, entre outros, não se pode afirmar que o composto estará maduro, quando a temperatura da biomassa atingir valores próximos a temperatura ambiente. Por sua vez, a diminuição da temperatura da biomassa 


\section{COMPOSTAGEM DE RESÍDUOS ORGÂNICOS}

poderá ocorrer em função de uma redução da umidade e/ou de uma menor concentração de nutrientes no substrato e/ou, ainda, devido a um menor tamanho das leiras, o que segundo Pereira Neto (2007), proporciona uma maior perda de calor para o ambiente. Dessa forma, a temperatura pode ser sim, um indicativo do equilíbrio microbiológico no interior da biomassa, que é proporcionado pela inter-relação entre fatores como umidade, tamanho da leira e partículas, disponibilidade de nutrientes, relação $\mathrm{C} / \mathrm{Ne}$ aeração.

Desta forma, eficiência da compostagem pode ser avaliada pela qualidade do composto produzido, que está diretamente relacionada ao fornecimento de condições ótimas para a multiplicação e o desenvolvimento de microrganismos, que determinam a fase em que se encontra o processo.

Segundo Rodrigues et al. (2006), a decomposição inicial é conduzida por microrganismos mesófilos, que utilizam os componentes solúveis e rapidamente degradáveis da matéria orgânica. Sendo assim, como o metabolismo dos microrganismos é exotérmico, parte do calor gerado, durante a oxidação da matéria orgânica, acumula-se no interior da leira (Tang et al., 2004), elevando a temperatura de $25^{\circ} \mathrm{C}$ para $40-45^{\circ} \mathrm{C}$, em um período de 2 a 3 dias (Kiehl, 1985), sendo que quando a temperatura atinge valores acima $\operatorname{dos} 45^{\circ} \mathrm{C}$, a atividade microbiológica mesofílica é suprimida pela implantação de uma comunidade microbiana termofílica (Tiquia, 2005). Miyatake e Iwabuchi (2006) avaliaram a relação entre a temperatura e a atividade microbiana na compostagem de esterco de bovinos leiteiros, em função da taxa de aeração. Os resultados indicaram que durante o período de elevação da temperatura de $20^{\circ} \mathrm{C}$ para 70 ${ }^{\circ} \mathrm{C}$, houve um pico no consumo de oxigênio entre $43^{\circ} \mathrm{C}$ e $60^{\circ} \mathrm{C}$, que foi atribuído ao aumento do número de microrganismos mesófilos quando a temperatura atingiu $40^{\circ} \mathrm{C}$ e a elevação da população de microrganismos termófilos a $60^{\circ} \mathrm{C}$.
Segundo Peixoto (1988) e Snell(1991), na fase termófila ocorre à máxima decomposição dos compostos orgânicos, sendo considerada uma fase de degradação ativa de polissacarídeos como o amido, a celulose e as proteínas, transformando-os em subprodutos que serão utilizados pela microbiota (Pereira Neto, 2007). A degradação do substrato, por parte dos microrganismos, acarreta a diminuição da relação $\mathrm{C} / \mathrm{N}$, que se encontra entre 15/1 e 18/1, sendo caracterizado como uma material bioestabilizado (Kiehl, 2004).

Porém, à medida que os estoques de $\mathrm{C}$ são exauridos, a temperatura decresce gradualmente, até igualar-se à temperatura ambiente (Vinneras e Jonsson, 2002). Nesta fase, surgem novamente as comunidades mesófilas, que irão atuar na humificação do composto (Zucconi e Bertoldi, 1986), através da degradação de compostos mais resistentes como a hemicelulose e a lignina (Tuomela et al., 2000), o que leva a obtenção de um produto final com $\mathrm{pH}$ variando entre 7,0 e 8,0 e com relação C/N de 10/1 (Kiehl, 1985).

Sendo assim, a qualidade de um composto pode ser medida por meio de sua estabilidade e humificação (Lima, 2006). Conforme Miller (1992), um composto humificado é aquele que não produz efeitos inibitórios ou fitotóxicos às plantas. Tiquia e Tam (1998) utilizando material proveniente de compostagem de cama de suínos, que recebeu a adição de dejetos líquidos, observaram que a fitotoxidade do material para a germinação de sementes é significativamente afetada pelo tempo de compostagem. No dia zero de compostagem, devido à alta toxicidade do material, praticamente não ocorreu germinação das sementes e, no $49^{\circ}$ dia de compostagem, a germinação chegou a valores de $80 \%$ e $100 \%$, similares ao controle. Este aumento no percentual de germinação se deve ao fato do processo de compostagem eliminar os fatores fitotóxicos, à medida que ocorre a maturação do material. No entanto, a maturação completa não é desejável, porque o valor do composto orgânico como adubo depende em parte do 


\section{VALENTE ETAL.}

seu conteúdo orgânico (Huang et al., 2004).

Como foi dito anteriormente, a eficiência da compostagem é dependente da atividade microbiana, que além de produzir as transformações físicas e químicas no material compostado, também provoca a elevação da temperatura no interior da leira, o que também ocasiona a redução de microrganismos patogênicos, sendo um dos grandes objetivos desta tecnologia. Neste sentido, Mari et al. (2003) afirmam que a taxa de degradação é o resultado da atividade metabólica proveniente de uma população microbiana heterogênea, que se desenvolvem em diferentes temperaturas ótimas, levando a uma estabilização do material (Adani et al., 2003). Vespa (2005) avaliou a compostagem de lixo urbano produzido no município de São José do Rio Preto/SP e observou que durante os primeiros 30 dias de compostagem ocorreram temperaturas acima de $40^{\circ} \mathrm{C}$ no interior das leiras, que apresentavam dimensões de $1 \mathrm{~m}$ de altura, 1,5 $\mathrm{m}$ de largura e comprimento dependente da quantidade da material. Verificou que a partir da quarta semana de compostagem ocorreram temperaturas abaixo de $40^{\circ} \mathrm{C}$. No entanto, após dez semanas da instalação do experimento, houve novo aumento da temperatura no interior das pilhas. Já, Silva (2005) trabalhando com a compostagem de diferentes combinações de resíduos oriundos do processamento de plantas medicinais com esterco bovino verificou que em todas as pilhas, a temperatura aumentou rapidamente nos primeiros dias, indicando que o processo de compostagem estava se desenvolvendo adequadamente, sendo que já na primeira semana todos os materiais alcançaram temperaturas entre 50 e $60^{\circ} \mathrm{C}$, permanecendo até os 40 dias, quando a temperatura começou a cair, voltando à fase mesófila.

De outra forma, sabe-se da importância em se respeitar os limites máximos de temperatura, para que ocorra a redução de microrganismos patogênicos. Neste sentido, temperaturas acima de $50^{\circ} \mathrm{C}$ proporcionam condições desfavoráveis para a sobrevivência e para o desenvolvimento dos microrganismos patogênicos, que geralmente são mesofílicos (Finstein et al., 1987; Keener et al.,2000 citado por Sivakumar et al., 2007). Porém, temperaturas acima de $70^{\circ} \mathrm{C}$, por longos períodos, são consideradas desaconselháveis porque restringem o número de microrganismos na massa de compostagem, podendo ocasionar a insolubilização de proteínas hidrossolúveis e o desprendimento de amônia, principalmente quando o material possui baixa relação $\mathrm{C} / \mathrm{N}$, sendo um caso típico da compostagem de esterco de frangos (Kiehl, 1985; 2004).

Abouelwafa et al., (2008) afirmam que a compostagem pode ser efetivo na redução da concentração de patógenos, mas nem sempre consegue alcançar a sanitização do material. Neste sentido, Symanski (2005) analisando o material proveniente de uma leira de compostagem de resíduo sólido urbano da usina de compostagem do município de Porto Alegre/RS, verificou a presença de quatro espécies do gênero Enterobacter, das quais apenas a E. dissolvens não é tida como patogênica, sendo as demais, importantes causadoras de bacteremia em ambientes hospitalares. Baseado nestes resultados, podemos constatar que possivelmente as temperaturas de aproximadamente $65^{\circ} \mathrm{C}$, que ocorreram durante o período experimental, não foram suficientes para destruir esses microrganismos. Por outro lado, em alguns estudos com coliformes totais e fecais, Hassen et al. (2001) constataram um crescimento secundário desses microrganismos durante a compostagem, sendo atribuído a uma recontaminação do material durante o manuseio ou a estocagem do produto de forma incorreta.

Mesmo assim, a compostagem é mais eficiente quando se mantém temperaturas termófilas, porque reduz um maior número de microrganismos patogênicos, além de diminuir os fatores fitotóxicos, que inibem a germinação de sementes, concordando com Bari e Koenig (2001) que afirmam que esta tecnologia visa à obtenção de um produto final mais homogêneo, com maior valor ferti- 


\section{COMPOSTAGEM DE RESÍDUOS ORGÂNICOS}

lizante e higienicamente seguro. Zhu (2007) avaliando o efeito da baixa relação $\mathrm{C} / \mathrm{N}$ na compostagem da mistura de dejetos de suínos e casca de arroz verificou que o composto atingiu a maturidade durante a fase termófila, sendo que esta também contribuiu para a eliminação dos microrganismos patogênicos.

Por outro lado, a avaliação da maturidade de compostos orgânicos tem sido reconhecida como um dos mais importantes problemas relacionados ao processo de compostagem e utilização agrícola segura do produto final. Garcia-Gomez et al. (2005) afirmam que é um desafio a utilização de métodos precisos para avaliar a maturidade desses compostos. Negro et al. (2000) complementam, quando afirmam que é difícil avaliar a maturação de um composto a partir de um único parâmetro químico, bioquímico e toxicológico, já que o processo de compostagem é microbiológico e muito complexo.

Diversas pesquisas abordam os vários métodos existentes para avaliar o grau de maturidade de um composto. Jiménez e Garcia (1989) afirmam que a redução do conteúdo total da matéria orgânica é determinada através da concentração de sólidos totais e voláteis, do teor de cinzas, da demanda bioquímica de oxigênio e da relação $\mathrm{C} / \mathrm{N}$, sendo frequentemente utilizados como métodos para medir o grau de maturidade do composto. Porém, sabe-se que estes parâmetros dependem das características do material a ser compostado, podendo ser utilizados somente em situações onde não há grandes variações na composição deste material. Rivera-Rosário (2003) afirmam que materiais suficientemente maduros têm sido compostados, mostrando variações de 5:1 a 20:1, dependendo do tipo de material, o que faz com que este parâmetro não seja considerado como um indicador absoluto de maturação. Goyal et al. (2005) estudaram as mudanças químicas e biológicas durante a compostagem de diversos resíduos e concluíram que não pode ser utilizado um único parâmetro para avaliar o grau de maturidade de um composto. Ainda, afirmam que a relação $\mathrm{C} / \mathrm{N}$ pode ser utilizada como um índice confiável de maturidade do composto, desde que combinada com outros parâmetros como o $\mathrm{CO}_{2}$ evoluído, o carbono solúvel em água e o teor de substâncias húmicas.

Portanto, a necessidade de dispor de parâmetros que fossem independentes das características do substrato, levou ao desenvolvimento de métodos que medissem a fração de compostos disponíveis à decomposição pelos microrganismos. Estes métodos são baseados na hipótese de que a maturidade do composto pode ser estimada pela estabilidade biológica do produto.

Desta forma, um dos métodos utilizados é a respirometria, que se baseia na medida do oxigênio consumido, sob condições não limitantes de disponibilidade de nutrientes, de oxigênio, de umidade e de $\mathrm{pH}$ (Haug e Ellworth, 1991). Huang et al. (2004) afirmam que a taxa de consumo de oxigênio é proporcional à taxa de decomposição da matéria orgânica, que érealizada pelos microrganismos heterotróficos, que convertem as moléculas orgânicas em inorgânicas. No caso do carbono, a mineralização se traduz pela liberação de $\mathrm{C}$ da matéria orgânica na forma de $\mathrm{CO}_{2}$ (Benito et al., 2006). Said-Pullicino et al. (2007) afirmam que a diminuição dos índices de respirometria, durante a compostagem, indica como os microrganismos conduzem a estabilização do teor de matéria orgânica na mistura compostada. $\mathrm{O}$ autor verificou que aos 13 dias de compostagem, o consumo de oxigênio alcançou o valor máximo de 27,5 $\mathrm{mg} \mathrm{O}_{2} \cdot \mathrm{g}^{-1} \cdot \mathrm{MS} \cdot \mathrm{h}^{-1}$, sendo que logo após, foi diminuindo gradualmente, alcançando $1,9 \mathrm{mg}$ $\mathrm{O}_{2} \cdot \mathrm{g}^{-1}$.MS.h $\mathrm{h}^{-1}$ aos 250 dias de compostagem, indicando que o composto estava estabilizado. Entretanto, Miyatake e Iwabuchi (2006) concluíram que um composto com uma taxa de consumo de $100 \mathrm{mg} \mathrm{O} \cdot \mathrm{kg}^{-1} \cdot \mathrm{MS}^{-1}$ seria aceitável para ser utilizado na maioria das aplicações deste produto. Porém, também sugerem que uma taxa de $20 \mathrm{mg} \mathrm{O}_{2} \cdot \mathrm{kg}^{-1}$.MS.h 


\section{VALENTE ETAL.}

${ }^{1}$ seria desejável para uso em horticultura. De outra forma, Morrel et al. (1985) propuseram o valor de $40 \mathrm{mg} \mathrm{O}_{2} \cdot \mathrm{kg}^{-1}$. MS.h ${ }^{1}$. Já, Feldman (1995) afirma que em um índice de estabilidade entre 5 e $10 \mathrm{mg} \mathrm{CO}-\mathrm{C} \cdot \mathrm{g}^{-1}$ C. dia $^{-1}$, há alto potencial de fitotoxidade, imobilização de nitrogênio, sendo considerado um composto imaturo. De um modo geral, pode-se perceber que não existe um consenso sobre que valor define a estabilidade de um composto, devendo ser associado a outros métodos de avaliação.

Além destes indicadores, a maturação do composto está diretamente relacionada com a proporção de substâncias húmicas presentes, que compreende a humina, os ácidos húmicos e os ácidos fúlvicos. Tuomela et al. (2000) afirmam que em geral, o composto imaturo contém altos níveis de ácido fúlvico e menos níveis de ácidos húmicos. Entretanto, Tomati et al. (2002) afirmam que no início do processo de maturação, que ocorre na fase mesófila (Zucconi e Bertoldi, 1986), a fração de ácidos fúlvicos é elevada, por ser a primeira a ser sintetizada. Em outro sentido, GarciaGomez et al. (2005) afirmam que a redução da fração de ácidos fúlvicos sugere que a transformação de substâncias, que ocorre durante a compostagem, gera estruturas mais complexas e polimerizadas, que são correspondentes às substâncias húmicas, concordando com Cayuela et al. (2006) que afirmam que a fração de ácido fúlvico diminui, enquanto que os ácidos húmicos são produzidos.

A humificação gradual e a maturidade do composto podem ser estimadas pelo índice de humificação, estimado pela relação ácido húmico/ácido fúlvico (AH/AF) (IglesiasJimenez e Perez-Garcia, 1992). Os autores afirmam que quando a relação $\mathrm{AH} / \mathrm{AF}$ é superior a 1, haverá predomínio de $\mathrm{AH}$ e, quanto mais alto este valor maior será o grau de polimerização das substâncias húmicas. Chen et al. (1996) estudou a formação e as propriedades das substâncias húmicas durante a compostagem e verificou que o índi- ce de humificação aumentou durante o processo. Também, Garcia-Gómez et al. (2005) estudando a evolução das frações da matéria orgânica na compostagem encontraram valores de índice de humificação que variaram entre 0,5 e 2,0, sendo esses valores significativamente diferentes entre os compostos avaliados. Porém Francou et al. (2005) também estudaram a estabilização da matéria orgânica durante a compostagem e encontraram valores para o índice de humificação, que variaram entre 1,2 e 4,3 em diferentes materiais após 6 meses de compostagem.

Baseado nos resultados dos estudos desenvolvidos, pode-se dizer que é difícil estabelecer um valor universal para avaliar o grau de humificação, já que a degradação das frações orgânicas depende da origem e da composição da mistura do material compostado, o que concorda com Bernal et al. (1998). Além disso, outra limitação é necessidade da utilização de equipamentos sofisticados para realizar as técnicas espectroscópicas.

Conforme Roig et al.(1988), a capacidade de troca catiônica (CTC) também permite inferir o grau de maturação dos compostos, uma vez que o aumento da CTC está relacionado com os grupos funcionais das substâncias húmicas, produzidos durante o processo de humificação da matéria orgânica (Cegarra et al., 1983). Isto ocorre porque as substâncias húmicas, que compõe o composto, são colóides eletronegativos com grande superfície específica.

Melo et al. (2008) estudaram a matriz orgânica de amostras de lodo de esgoto e de estercos de aves, suínos, codornas e bovinos. Os autores verificaram que a CTC dos resíduos variou de 4,9 a 97,3 cmolc $\mathrm{kg}^{-1}$, refletindo a grande variação na capacidade desses materiais orgânicos em adsorver cátions. Também, observaram que quanto maior o teor de C-fração ácido húmico, mais elevada é a CTC dos resíduos orgânicos. Considerando os valores encontrados pelo autor, pode-se perceber que esse atributo 


\section{COMPOSTAGEM DE RESÍDUOS ORGÂNICOS}

reflete grandes diferenças no grau de maturação dos resíduos, sendo dependente da origem e da composição das misturas utilizadas no processo de compostagem.

Desta forma, Iglesias-Jimenez e PerezGarcia (1992) estabeleceram o valor mínimo de 67 cmolc $\mathrm{kg}^{-1}$ para um composto de lixo urbano ser considerado decomposto, ou seja, estável do ponto de vista bioquímico.

De um modo geral, podemos dizer que, pelos relatos encontrados na literatura, até o momento, não existe consenso sobre um método único, aceito de forma generalizada para determinar a qualidade de um composto. Há trabalhos usando diversos parâmetros que informam, de maneira relativa, a evolução da matéria orgânica durante o processo, ou como indicativo da qualidade do produto para a venda. Em todos os casos podem existir problemas, já que um parâmetro poderia ser um bom indicador do grau de maturação do ponto de vista teórico, mas inaplicável por sua perda de significância ao ignorar a procedência da amostra, ou por não ser aplicável em análises de rotina. De acordo, Tomati et al. (2000) e Jouraiphy et al. (2005) ressaltam que para inferir o grau de maturação de resíduos orgânicos, o ideal é que várias características sejam analisadas de modo conjunto.

Além disso, pode-se dizer que a qualidade do produto final da compostagem deve ser normatizada por legislação específica de cada País, pois o composto não é um produto único, podendo sua qualidade variar de acordo com os resíduos orgânicos e os processos empregados.

\section{GRANULOMETRIA}

A granulometria, ou dimensão das partículas, é uma importante característica a ser considerada, pois interfere no processo de compostagem. A decomposição da matéria orgânica é um fenômeno microbiológico cuja intensidade está relacionada à superfície específica do material a ser compostado, sendo que quanto menor a granulometria das partículas, maior será a área que poderá ser atacada e digerida pelos microrganismos, acelerando o processo de decomposição (Kiehl, 1985; Keener e Das, 1996; Fernandes e Silva, 1999).

Desta forma, em um primeiro momento, constata-se que partículas mais finas seriam as mais adequadas ao processo de compostagem. Porém, Pereira Neto (1996) comenta que se condições como compactação e anaerobiose não prejudicassem o andamento do processo, as dimensões teoricamente ideais seriam mesmo as microscópicas. Desta forma, Rodrigues et al. (2006) explicam que materiais com granulação muito fina geram poucos espaços porosos, dificultando a difusão de oxigênio no interior da leira, favorecendo assim o surgimento de condições anaeróbias, que é proporcionada pela presença de uma maior quantidade de microporos, levando a uma compactação e um aumento da densidade do substrato compostado (Primavesi, 1981; Kiehl, 2004).

De acordo, Leite (1997) afirma que o alto teor de umidade e a baixa granulometria são parâmetros que podem contribuir para a elevação da densidade da fração orgânica putrescível dos resíduos. Sabe-se que com o aumento da densidade, ocorre uma diminuição na eficiência do processo, que pode estar relacionada com a dificuldade de distribuição dos microrganismos, das enzimas e outros metabólitos microbianos, devido ao alto grau de compactação dos substratos e o alto teor de umidade (Tuomela et al., 2000).

Desta forma, corroborando das afirmações, Raiv et al. (1986) afirmam que, também a distribuição do tamanho das partículas e a porosidade entre as partículas afetam o balanço entre o conteúdo de água e o ar para cada nível de umidade. Ahn et al. (2008) investigaram os parâmetros físicos de compostos obtidos de compostagem em larga-escala e concluíram que a porosidade diminui de acordo com o aumento da densidade aparente, do teor de umidade e da capacidade de absorção do material 


\section{VALENTE ETAL.}

compostado. Da mesma forma, Handreck (1983) estudou o tamanho das partículas e as propriedades físicas e concluiu que partículas menores que $0,5 \mathrm{~mm}$ e, em particular, entre 0,1 e $0,25 \mathrm{~mm}$, tiveram uma maior influência sobre a porosidade a retenção de água. Benito et al. (2006) avaliaram a compostagem de resíduos de podas de árvores e constataram que o melhor substrato foi aquele que apresentou partículas grosseiras, entre $0,25 \mathrm{e} 2,5 \mathrm{~mm}$, pois permitiu uma melhor taxa de umidade e uma adequada aeração. Por outro lado, Pereira Neto (1988) afirma que o tamanho ideal das partículas encontra-se entre 20 e $80 \mathrm{~mm}$. Entretanto, anos mais tarde, Pereira Neto (2007) conclui que as partículas da massa em compostagem devem situar-se entre 10 e $50 \mathrm{~mm}$.

De modo semelhante ao que acontece com o teor de umidade, o teor de oxigênio e a relação $\mathrm{C} / \mathrm{N}$, o estabelecimento da granulometria ótima para a compostagem é bastante difícil, uma vez que cada material a ser compostado apresenta particularidades. Misturar vários tipos de resíduos orgânicos parece ser a maneira mais adequada para tentar corrigir o tamanho das partículas, favorecendo a homogeneização da massa em compostagem, obtendo assim uma melhor porosidade, o que acarretará uma menor compactação devido à maior capacidade de aeração. Além disso, aumentando-se a área superficial para a degradação, diminuirá o tempo de compostagem. Desta forma, Ruggieri et al. (2008) afirmam que as características físicas da mistura inicial são decisivas para o bom desenvolvimento do processo de compostagem.

Entretanto, Richard et al.(2002) ressaltam que partículas com dimensões maiores, como aparas de madeira, ajudam a manter a aeração da leira, mas fornecem menos $\mathrm{C}$ disponível por massa de material, afetando a atividade dos microrganismos. Desta forma, mesmo que quantidades iguais de $\mathrm{C}$ estejam contidas em massas idênticas de aparas de madeira e serragem, a maior superfície da serragem fará com que o C nela contido, seja mais disponível aos microrganismos (Lynch e Wood, 1985). Neste sentido, Lhadi et al. (2006) estudaram a evolução da matéria orgânica durante a compostagem da mistura da fração orgânica de resíduos municipais e esterco de aves. A mistura básica inicial dos resíduos foi de $3: 2$, ou seja, $3 \mathrm{~kg}$ de resíduos municipais e $2 \mathrm{~kg}$ de esterco de aves, com granulometria de $1 \mathrm{~cm}$, correspondendo assim a leira $\mathrm{A}$, sendo que para a leira $\mathrm{B}$, foi utilizado a proporção de 2:3, com granulometria de $0,2 \mathrm{~cm}$. Através dos resultados obtidos, os autores verificaram que as diferentes proporções não influenciaram a composição da matéria orgânica final do composto. No entanto, parece que houve influência do tamanho das partículas que apresentaram $0,2 \mathrm{~cm}$, sendo atribuído ao aumento da degradação dos compostos, concordando com Lynch e Wood (1985).

Segundo Georgacakis et al. (1996), os resíduos provenientes de dejetos de suínos possuem altos teores de fibra e umidade, requerendo assim a adição de agentes estruturantes, que apresentem pouca umidade. Os autores verificaram que há uma aceleração do processo, além da minimização de odores provenientes destes dejetos, com a adição de materiais com alto teor de lignina. A mistura básica inicial de esterco e lignina foi de $1: 1$, sendo que nesta proporção a umidade foi ajustada em 55-65\% e o odor foi reduzido. Além disso, os autores concluíram que a mistura de resíduos melhorou a eficiência do processo, além de beneficiar quimicamente os produtos obtidos. Entretanto, Tiquia e Tam (2000) trabalhando com compostagem de dejetos de suínos, utilizaram a proporção de $2: 1$, ou seja, duas partes de cama de aviário para uma parte destes dejetos, com aeração forçada, por um período de 77 dias. Porém, Lau et al. (1992) estudando a taxa e a freqüência de aeração em sistemas de compostagem de dejetos de suínos, recomendam a proporção de $5: 1$, isto é, cinco partes de cama de aviário para uma parte de dejetos. 


\section{COMPOSTAGEM DE RESÍDUOS ORGÂNICOS}

Um importante fator a ser considerado, quando se realiza a mistura dos substratos é a capacidade de absorção dos materiais utilizados como agentes estruturantes, bem como a relação $\mathrm{C} / \mathrm{N}$ da mistura inicial. No caso das pesquisas realizadas por Lau et al. (1992) e Tiquia e Tam (2000) não ficou claro o tipo material celulósico utilizado como cama para as aves. Sabe-se que casca de arroz, a maravalha e a serragem são os materiais mais utilizados na avicultura brasileira, sendo que cada um desses apresentam particularidades diferentes, como a relação $\mathrm{C} / \mathrm{N}$ e a capacidade de absorção de líquidos, o que explica a diferença nas proporções das misturas. Neme et al. (2000), afirmam que a maravalha apresenta densidade média de $85 \mathrm{~kg} / \mathrm{m}^{3}$ e granulometria média de aproximadamente 2,4 mm, enquanto que a serragem apresenta densidade média de $198 \mathrm{~kg} / \mathrm{m}^{3}$ e granulometria média de 1,23 mm (Dai Prá, 2006). Baseado nestes dados se verifica que a serragem por apresentar uma maior densidade e menor tamanho de partículas, possui uma maior capacidade de absorção de líquidos. Por outro lado, apresenta uma maior probalidade de levar a compactação da mistura, afetando assim o desenvolvimento de microrganismos aeróbios, o que prejudicará o aumento da temperatura durante o processo.

De outra forma, Gorgatti (2001) ao pesquisar a compostagem da mistura de resíduos de plantas medicinais e esterco bovino, utilizou as dejeções na proporção que equilibrasse a relação $\mathrm{C} / \mathrm{N}$ em $30 / 1$, que conforme Kiehl (2004) é considerada a ideal para o bom desenvolvimento da compostagem. Também, Costa et al. (2006) estudando o processo de compostagem de carcaças avícolas, utilizaram a proporção de $3: 1$, ou seja, para cada $3 \mathrm{~kg}$ de cama de aviário foram adicionados $1 \mathrm{~kg}$ de carcaças de aves mortas. Já, Sivakumar et al. (2007) utilizaram na compostagem de carcaças de aves, a proporção de $3: 1: 1,75$; ou seja, para cada 3 $\mathrm{kg}$ de excretas de aves foram adicionados 1 $\mathrm{kg}$ de carcaça e $1,75 \mathrm{~kg}$ de palha. Entretanto, mais importante do que uma relação $\mathrm{C} / \mathrm{N}$ ideal, é a granulometria das partículas , bem como a sua porosidade, visto que partículas muito finas e o aumento dos microporos facilitam o aumento da umidade, o que acarreta a anaerobiose do material compostado.

\section{DIMENSÕES DAS LEIRAS}

O correto dimensionamento das leiras é também de suma importância para a compostagem de resíduos orgânicos, independente de sua origem e composição. Uma leira de compostagem deve ter um tamanho suficiente para impedir a rápida dissipação de calor e umidade e, ao mesmo tempo, permitir uma boa circulação de ar (Rodrigues et al., 2006). De acordo com Kiehl (2004), a altura do material deve estar entre 1,5 m e 1,8 m. Entretanto, Nunes (2003) verificou que em leiras com dimensões de 2,60 m de comprimento, 2,00 $\mathrm{m}$ de largura e $1,00 \mathrm{~m}$ de altura, as temperaturas mantiveramse entre $40^{\circ} \mathrm{C}$ e $55^{\circ} \mathrm{C}$ por um longo período, sendo registradas elevações médias de $10^{\circ} \mathrm{C}$, imediatamente após a incorporação de dejetos aos substratos maravalha e serragem.

Costa et al. (2006), em experimento com o objetivo de avaliar a compostagem de carcaças de aves em células com e sem aeração, onde as células foram preenchidas com os materiais até a altura de $1,80 \mathrm{~m}$, observaram que as temperaturas mantiveramse entre $40^{\circ} \mathrm{C}$ e $70^{\circ} \mathrm{C}$, para ambos os sistemas. De outra forma, Valente (2008) avaliou a compostagem de carcaças de fêmeas de frangos de corte e de cortes nobres de fêmeas de frangos de corte, utilizando cama de aviário como material celulósico. Após a realização da primeira fase da compostagem, foram formadas leiras de 1,60 m de largura, $1,00 \mathrm{~m}$ de altura e 3,00 $\mathrm{m}$ de comprimento, sendo os revolvimentos realizados a cada 18 dias, bem como a adição de água à massa em compostagem. $\mathrm{O}$ autor verificou que a temperatura variou de $40^{\circ} \mathrm{C} \mathrm{e} 70^{\circ} \mathrm{C}$, aumentando imediatamente após cada revolvimento e diminuindo posteriormente, sendo atribuído 
a diminuição do teor de umidade no interior das leiras.

Dessa forma, de acordo com o material a ser compostado, a altura das leiras deve ser estabelecida. Entretanto, uma altura mínima de $0,80 \mathrm{~m}$ deve ser respeitada, abaixo da qual não existem condições adequadas para a formação e manutenção da temperatura.

\section{CONCLUSÃO}

A compostagem de resíduos orgânicos é afetada pela interdependência e pelo interrelacionamento de fatores como o teor de umidade, a taxa de oxigênio, a relação $\mathrm{C} / \mathrm{N}$, a granulometria e a porosidade do material a ser compostado, sendo estes afetados pelo manejo adotado. Entretanto, estabelecer condições ótimas de granulometria, porosidade, relação $\mathrm{C} / \mathrm{N}$ e teor de umidade, bem como inter-relacionar estas condições é bastante difícil, uma vez que cada material a ser compostado apresenta particularidades. Desta forma, a mistura de vários tipos de resíduos orgânicos é a maneira mais adequada de tentar balancear a relação $\mathrm{C} / \mathrm{N}$ e a granulometria, que além dos nutrientes necessários para o desenvolvimento microbiano, favorecerá também a homogeneização da massa em compostagem, obtendo assim uma melhor porosidade, o que acarretará uma menor compactação devido à maior capacidade de aeração. Sendo assim, é de extrema importância a análise físico-química da mistura inicial.

O pH ácido dos resíduos orgânicos é um fator que não deve ser levado em consideração quando se procura estabelecer condições

\section{BIBLIOGRAFIA}

Abid, N. and S. Sayadi. 2006. Detrimental effects of olive mill wastewater on the composting processo for agricultural wastes. Waste Manage., 26: 1099-1107.

Abouelwafa, R., G.A, Baddi, S. Souabid, P. Winterton, J. Cegarra and M. Hafidi. 2008. Aerobic biodegradation of sludge from the adequadas para o desenvolvimento da compostagem, já que durante o processo ocorre diversas reações químicas do tipo ácido-base e de óxido-redução que irão regular está acidez, gerando um produto final com $\mathrm{pH}$ entre 7,0 e 8,5. De outra forma, a relação $\mathrm{C} / \mathrm{N}$ ideal não deve ser considerada um valor absoluto, já que é dependente da qualidade de carbono disponível para os microrganismos.

A atividade microbiana no interior da massa em compostagem ocorre na presença de quantidades muito reduzidas de oxigênio, sendo que a ausência de revolvimentos não é um fator prejudicial para o desenvolvimento do processo. No entanto, ele se faz necessário no caso da compostagem de resíduos líquidos, sendo utilizado para acelerar a evaporação do excedente de umidade. Neste caso a escolha de resíduos orgânicos que servirão de agentes estruturantes se faz necessário, devendo-se levar em conta a sua capacidade de absorção.

A elevação da temperatura é um indicativo do equilíbrio microbiológico, porém não pode ser utilizada como parâmetro de maturidade do composto. A avaliação da maturidade de compostos orgânicos deve ser realizada, associando-se vários parâmetros já que a degradação das frações orgânicas depende da origem e da composição da mistura inicial compostada. Além disso, conclui-se que a qualidade do produto final da compostagem deve ser normatizada por legislação específica de cada País, pois o composto não é um produto único, podendo sua qualidade variar de acordo com os resíduos orgânicos e os processos empregados.

effluent of a vegetable oil processing plant mixed with household waste: physical-chemical, microbiological and spectroscopic analysis. Bioresource Technol., 99: 8571-8577.

Adams, J.D.W. and L.E. Frostick. 2008. Investigating microbial activities in compost using mushroom (Agarícus bísporus) cultivation as an experi- 


\section{COMPOSTAGEM DE RESÍDUOS ORGÂNICOS}

mental system. Bioresource Technol., 99: 10971102.

Adani, F., G. Gigliotti, F. Valentini and R. Laraia. 2003. Respiration índex determination: a comparative study of differente methods. Compost. Sci. Util., 11: 144-151.

Ahn, K.K, T.L. Richard and T.D. Glanville. 2008. Laboratory determination of compost physical parameters for modeling of airflow characteristics. Waste Manage., 28: 660-670.

Aquino, A.M. de., D.L. de. Almeida, J.G.M. Guerra e H. De-Polli. 2005. Biomassa microbiana, colóides orgânicos e nitrogênio inorgânico durante a vermicompostagem de diferentes substratos. Pesq. Agropec. Bras., 40: 10871093.

Amine-Khodja, A., O. Trubetskaya, O. Trubetskoy, L. Cavani, C. Ciavatta and G. Guyot. 2006. Humic-like substances extracted from composts can promote the photodegradation of irgarol 1051 in solar light. Chemosphere, 62: 10211027.

ANUALPEC. 2008. Anuário da pecuária brasileira. FNP. Consultoria e Comércio, ed. Argos Comunicação. São Paulo. 400 p.

Baird, C. 2002. Química Ambiental, 2.ed. Bookman. Porto Alegre. p. 463-473.

Bari, Q.H. and A. Koening. 2001. Effect of air reciculation and reuse on composting of organic solid waste. Resour. Conserv. Recy., 33: 93111.

Barrington, S., D. Choinere, M. Trigui and W. Knight. 2002. Effect of carbon source on compost nitrogen and carbon losses. Bioresource Technol., 83: 189-194.

Barrington, S., D. Choinére, M. Trigui and W. Knight. 2003. Compost convective airflow under passive aeration. Bioresource Technol., 86: 259-266.

Beltrane, K.G. e F.J.P. de C. Carvalho. 2006. Comparação de padrões de qualidade de composto orgânico entre diferentes países. In: C.A. Spadotto e W. Ribeirio (orgs.). Gestão de resíduos na agricultura e agroindústria. FEPAF. Botucatu. p. 118-137.

Benito, M.A., A. Masaguer and R. de A. Moliner. 2006. Chemical and physical properties of pruning waste compost and their seasonal variability. Bioresource Technol., 97: 20712076.
Bernal, M.P., C. Paredes, M.A. Sanchez-Monedero and J. Cegarra. 1998. Maturity and stability parameters of composts prepared with a wide range of organic wastes. Bioresource Technol., 63: 91-99.

Bidone, F.R.A. 2001. Resíduos sólidos provenientes de coletas especiais: Eliminação e valorização. Associação Brasileira de Engenharia Sanitária e Ambiental, ABES. Rio de Janeiro. Brasil.

Brasil. 2004. Constituição da República Federativa do Brasil de 1988. Câmara dos Deputados. Brasília. $160 \mathrm{p}$.

Bünemann, E.K., D.A Bossio, P.C. Smithson, E. Frossard and A. Oberson. 2004. Microbial community composition and substrate use in a highly weathered soil as affected by crop rotation and $\mathrm{P}$ fertilization. Soil Biol. Biochem., 36: 889-901.

Carneiro, J.G. de. A. 1995. Produção e controle da qualidade de mudas florestais. UFPR/FUPEF. Curitiba. $451 \mathrm{p}$.

Cayuela, M.L., M.A. Sánchez-Monedero and A. Roig. 2006. Evaluation of two different aeration systems for composting two-phase olive mill wastes. Process Biochem., 41: 616-623.

Chanyasak, V. and Kubota, H. 1981. Carbon/ organic nitrogen ratio in water extracts as a measure of composting degradation. J. Ferment. Technol., 59: 215-221.

Chanyasak, V., M. Hirai and H. Kubota. 1982. Changes of chemical components and nitrogen transformation in water extracts during composting garbage. J. Ferment. Technol., 60: 439-446.

Chen, Y., B. Chefetz and Y. Hadar. 1996. Formation and properties of humic substance originating from compost. In: Bertoldi, M., P. Sequi, B. Lemmes, T. Papi (Eds.). European Comission International Symposium. The Science of Composting. Blackie Academic \& Professional. England. p. 382-393.

Cegarra, J.L., M.T. Hernández, A. Lax y F. Costa. 1983. Adición de resíduos vegetales a suelos calizos: influéncia sobre la capacidad de cambio catiônico. An. Edafol. Agrobiol., 42: 235-244.

Corrêa, D., F.P. Pressi, M.L.G. Jacometti e P.I. Spitzner. 1982. Tecnologia de fabricação de fertilizantes orgânicos. In: Cerri, C.C.; D. Athié. The regional colloquium on soil organic matter 


\section{VALENTE ETAL.}

studies. Proceedings... São Paulo. p. 217-222. Corrêa, E.K. 1998. Avaliação de diferentes tipos de camas na criação de suínos em crescimento e terminação. Dissertação (Mestrado em Zootecnia). Faculdade de Agronomia Eliseu Maciel, Universidade Federal de Pelotas. Pelotas. 91 p.

Corrêa, E.K. 2003. Produção de suínos sobre cama. Gráfica Universitária. UFPEL. Pelotas. $75 \mathrm{p}$.

Costa, M.S.S. deM. 2005. Caracterização dos dejetos de novilhos superprecoces: reciclagem energética e de nutrientes. Tese (Doutorado em Agronomia). Faculdade de Ciências Agronômicas. Universidade Estadual Paulista "Júlio de Mesquita Filho". Botucatu. 98 p.

Costa, M.S.S. de M., L.A. de M. Costa, A. Pelá, C.J. da Silva, L.D. Decarli e U.F Matter. 2006. Desempenho de quatro sistemas para compostagem de carcaças de aves. Rev. Bras. Engenh. Agríc. Amb., 10: 692-698.

Dai Prá, M.A. 2006. Desenvolvimento de um sistema de compostagem para o tratamento de dejetos de suínos. Dissertação (Mestrado em Zootecnia). Faculdade de Agronomia Eliseu Maciel. Universidade Federal de Pelotas. Pelotas, RS. $127 \mathrm{p}$.

Deon, M., J.L. Mattias, C.N. Nesi e D.F. Kolling. 2007. Avaliação da qualidade de composto orgânico na Universidade Comunitária Regional de Chapecó. Rev. Bras. Agroecol., 2: 14411444.

Dinel, H., G.R. Mehuys and M. Lévesque. 1991. Influence of humic and fibric materials on the aggregation and aggregate stability of lacustrine silty clay. Soil Science, 151: 146-158.

Ecochem. Composting process. 2004. http:// www.ecochem.com/t_compost_faq2.html. Acesso em: 2/7/2004.

Eggen, T. and O. Vethe. 2001. Stability indices for different composts. Compost Sci. Util., 9: 1926.

Emerson, D. 2004. Single stream vs. source separated recycling. Biocycle, 5: 22

Feldman, K. 1995. Stability index determination. Biocycle, 36: 68-69.

Fernandes, F. e S.M.C.P. da Silva. 1999. PROSAB - Programa de pesquisa em saneamento básico. Manual prático para a compostagem de biossólidos. ABES -Associação Brasileira de Engenharia Sanitária e Ambiental. Rio de Janeiro. Finstein, M.S., F.C. Miller, J.A. Hogan and P.A.
Strom. 1987. Analysis of EPA guidance on sludge composting. Part I- Biological heat generation and temperature. Biocycle, 28: 56-61.

Fiori, M.G.S., M. Schoenhals e F.A.C. Follador. 2008. Análise da evolução tempo-eficiência de duas composições de resíduos agroindustriais no processo de compostagem aeróbia. Engenh. Amb., 5: 178-191.

Fong, M., J.W.C. Wong and M.H. Wong. 1999. Review on evaluation of compost maturity and stability of solid waste. Shanghai Environ. Sci., 18: 91-93.

Francou, C., M. Poitrenaud and S. Houot. 2005. Stabilization of organic matter during composting: influence of process and feedstocks. Compost. Sci. Util., 13: 72-83.

Garcia-Gomez, A., M.P. Bernal and A. Roig. 2005. Organic matter fractions involved in degradation and humification processes during composting. Compost. Sci. Util., 13: 127-135.

Georgacakis, D., A. Tsavdaris, J. Bakouli and S. Symeonidis. 1996. Composting solid swine manure and lignite mixtures with selected plant residues. Bioresource Technol., 78: 107-109.

Gorgati, C.Q. 2001. Resíduos sólidos urbanos em áreas de proteção aos mananciais - município de São Lourenço da Serra - SP: compostagem e impacto ambiental. Tese (Doutorado em Agronomia). Universidade Estadual Paulista "Júlio de Mesquita Filho". Botucatu. 70 p.

Goyal, S., S.K. Dhull and K.K. Kapoor. 2005. Chemical and biological changes during composting of different organic wastes and assessment of compost maturity. Bioresource Technol., 96: 1584-1591.

Hassen, A., K. Belguith, N. Jedidi, A. Cherif and A. Boudabous. 2001. Microbial characterization during composting of municipal solid waste. Bioresource Technol., 80: 217-225.

Handreck, K.A. 1983. Particle size and the physical properties of growing media for containers. Commun. Soil Science. Plant. Anal., 14: 209222.

Haug, T.H. and W.F. Ellworth. 1991. Measuring compost substrate degradability. Evaluation of compost maturity. In: The biocycle guide to the art science of composting. J.G. Press. Emmaus. p. 188-194.

Haug, R.T. 1993. Practical handbook of compost engineering. Lewis Publishers. Boca Raton. 


\section{COMPOSTAGEM DE RESÍDUOS ORGÂNICOS}

$717 \mathrm{p}$.

Huang, G.F.A., J.W.C. Wong, Q.T. Wu and B.B. Nagar. 2004. Effect of $\mathrm{C} / \mathrm{N}$ on composting of pig manure with sawdust. Waste Manage., 24: 805-813.

Iglesias-Jimenez, E. and V. Perez-Garcia. 1992. Determination or maturity índices for city refuse composts. Agr. Ecosyst. Environ., 38: 331-343.

Isoldi, L.A. 1998. Remoção de nitrogênio de águas residuárias da industrialização de arroz por tecnologias performantes. Tese (Doutorado em Biotecnologia). Centro de Biotecnologia. Universidade Federal de Pelotas. Pelotas. $152 \mathrm{p}$.

Imbar, Y., Y. Che and Y. Hadar. 1990. Humic substances formed during the composting of organic matter. Soil Sci. Soc. Am. J., 54: 13161323.

Imbar, Y., Y. Hadar and Y. Cher. 1993. Recycling of catle manure: the composting process and characterization of maturity. J. Environ. Qual., 22: 857-863.

Jahnel, M.C., R. Melloni e E.J.B.N. Cardoso. 1999. Maturidade do composto de lixo. Sci. Agr., 56: 301-304.

Jahnel, M.C., R. Melloni e E.J.B.N. Cardoso. 2008. Maturidade de composto de lixo urbano. Scientia Agricola, 56. Disponível em: http://www.scielo.br. Acessado em: 12/02/2008.

Jiménez, E.I. and V.P. Garcia. 1989. Evaluation of city refuse compost stability: a review. Biol. Wastes, 27: 115-142.

Jouraiphy, A., S. Amir, M. El Gharous, J. Revel and M. Hafidi. 2005. Chemical and spectroscopic analysis of organic matter transformation during composting of sewage sludge and green plant waste. Inter. Biodet. Biodeg., 56: 101-108.

Kader, N.A.E., P. Robin, J.M. Paillat and P. Leterme. 2007. Turning, compacting and the addition of water as factors affecting gaseous emissions in farm manure composting. Bioresource Technol., 98: 2619-2628.

Keener, H.M. and K. Das. 1996. Process control based on dynamic properties in composting: moisture and compaction considerations. In: The science of composting. part 1. Chapman \& Hall. England. p. 116-125.

Kelleher, B.P., J.J. Leahy, A.M. Henihan, T.F. O'Dwyer, D. Sutton and M.J. Leahy. 2002. Advances in poultry litter disposal technology a review. Bioresource Technol., 83: 27-36.
Kiehl, E.J. 1985. Fertilizantes orgânicos. Editora Agronômica Ceres Ltda. Piracicaba. 492 p.

Kiehl, E.J. 2004. Manual de compostagem: maturação e qualidade do composto. $4^{\mathrm{a}} \mathrm{ed}$. $\mathrm{E}$. J. Kiehl. Piracicaba. 173 p.

Komilis, D.P. and R.K. Han. 2003. The effect of lignin and sugars to the aerobic decomposition of solid wastes. Waste Manage., 23: 419-423.

Komilis, D.P. and I.S. Tziouvaras. 2009. A statistical analysis to acess the maturity and stability of six composts. Waste Manage., 29: 1504-1513.

Kunz, A., M. Miele and R.L.R. Steinmentz. 2008. Advanced swine manure treatment and utilization in Brazil. Bioresource Technol, http:/ /www.sciencedirect.com. Acessado em: 12/ 03/2009.

Lau, A.K., K.V. Lo, P.H. Liao and J.C. Yu. 1992. Aeration experiments for swine waste composting. Bioresource Technol., 41: 145-152.

Lhadi, E.K., H. Tazi, M. Aylaj, P.L. Genenini and F. Adani. 2006. Organic matter evolution during co-composting of the organic fraction of municipal waste and poultry manure. Bioresource Technol., 97: 2117-2123.

Leita, L. and M. De Nobilli. 1991. Water-soluble fractions of heavy metal during composting of municipal solid waste. J. Environ. Qual., 20: 7378.

Leite, V.D. 1997. Processo de tratamento anaeróbio de resíduos sólidos urbanos inoculados com lodo de esgoto industrial. Tese (Doutorado em Hidráulica e Saneamento). Escola de Engenharia São Carlos/USP. São Carlos, 150 p.

$\mathrm{Li}, \mathrm{X}$., R. Zhang and Y. Pang. 2008. Characteristics of dairy manure composting with rice straw. Bioresource Technol., 99: 359-367.

Lima, M.A. 2002. Agropecuária brasileira e as mudanças climáticas globais: caracterização do problema, oportunidades e desafios. Cad. Ciência Tecnol., 19: 451-472.

Lima, C.C. de. 2006. Caracterização química de resíduos da produção de biodiesel compostados com adição mineral. Tese (Doutorado em Ciências). Universidade Federal de Viçosa. Viçosa. $167 \mathrm{p}$.

Lopez-Real, J. 1994. Composting through the ages. Conferência Down to Earth Composting. Dundee. Loureiro, D.C., A.M. de. Aquino, E. Zonta and E. Lima. 2007. Compostagem e vermicompostagem de resíduos domiciliares com esterco bovino 


\section{VALENTE ETAL.}

para a produção de insumo orgânico. Pesq. Agropec. Bras., 42: 1043-1048.

Lucas Júnior, J. de e T.M.B. dos Santos. 2003. Impacto ambiental causado pela produção de frangos de corte. In: Conferência Apinco de Ciência e Tecnologias Avícolas. Campinas, São Paulo. p. 107-121.

Lynch, J.M. and D.A. Wood. 1985. Controlled microbial degradation of lignocellulose: the basis for existing and novel approaches to composting. In: Gasser, J.K.R. Composting of agricultural and other wastes. Elsevier Applied Science. London. p. 183-193.

Mackenzie, M.D., T.H. De Luca and A. Sala. 2006. Fire exclusion and nitrogen mineralization in low elevation forests of westerm Montana. Soil Biol. Biochem., 38: 952-961.

Mari, I., C. Ehaliotis, M. Kotsu, C. Balis and D. Georgakakis. 2003. Respiration profiles in monitoring the composting of by-products from the olive oil agro-industry. Bioresource Technol., 87: 331-336.

Margesin, R., J. Cimadom and F. Schinner. 2006. Biological activity during composting of sewage sludge at low temperatures. Int. Biodet. Biodeg., 57: 88-92.

MAPA. 2005. Instrução Normativa nํ. 23, de 31 de agosto de 2005. Ministério da Agricultura, Pecuária e Abastecimento, Diário Oficial, Seção 1, p.12.

Melo, L.C.A., C.A Silva e B. de. O. Dias. 2008. Caracterização da matriz orgânica de resíduos de origens diversificadas. Rev. Bras. Ciênc. Solo, 32: 101-110.

Miller, F.C. 1992. Composting as a process base don the control of ecologically selective factors. In: Meeting, F.B. Soil Microb. Ecol., 18: 515543.

Miragliotta, M.Y., I. de A. NÄÄS, M. dos S. Baracho e M.E. Aradas. 2002. Qualidade do ar de dois sistemas produtivos de frangos de corte com ventilação e densidade diferenciadas - estudo de caso. Engenh. Agríc., 22: 1-10.

Miyatake, F. and K. Iwabuchi. 2006. Effect of compost temperature on oxygen uptake rate, specific growth rate and enzymatic activity of microorganisms in dairy cattle manure. Bioresource Technol., 97: 961-965.

Moreira, F.M.S. e J.O. Siqueira. 2002. Microbiologia e bioquímica do solo. UFLA. Lavras. 626pp.
Mondini, C., F. Fornasier and T. Sinicco. 2004. Enzymatic Activity as a parameter for the characterization of the composting process. Soil Biol. Biochem., 36: 1587-1594.

Morrel, J.L., F. Colin, J.C. Germon, P. Godin and C. Juste. 1985. Methods for evaluation of the maturity of municipal refuse compost. In: Gasser, J.K. Composting of agricultural and other wastes. Elsevier. London. p. 56-72.

Nascimento, R.A. 1996. Desempenho de reator anaeróbio de manta de lodo utilizando efluentes líquidos de indústria alimentícia. Dissertação (Mestrado em Engenharia Civil). Faculdade de Engenharia Civil. Universidade Estadual de Campinas. Campinas, $105 \mathrm{p}$.

Negro, M.J., F. Villa, J. Aibar, R. Alarcon e P. Ciria. 2000. Produção e gestão de composto. Informações Técnicas do Departamento de Agricultura de Zaragoza, 88: $32 \mathrm{p}$.

Neme, R., N.K. Sakomura, M.D.S. Oliveira, F.A. Longo e A.N. Figueiredo. 2000. Adição de gesso agrícola em três tipos de cama de aviário na fixação de nitrogênio e no desempenho de frango de corte. Rev. Ciênc. Rural, 30: 687692.

Nunes, M.L.A. Avaliação de procedimentos operacionais na compostagem de dejetos de suínos. 2003. Dissertação (Mestrado em Engenharia Ambiental). Faculdade de Engenharia Ambiental, Universidade Federal de Santa Catarina. Florianópolis. $101 \mathrm{p}$.

Peixoto, R.T. dos.G. 1988. Compostagem: opção para o manejo orgânico do solo. IAPAR. Londrina. $46 \mathrm{p}$.

Pereira Neto, J.T. 1988. Monitoramento da eliminação de organismos patogênicos durante a compostagem de resíduos urbanos e lodo de esgoto pelo sistema de pilhas estáticas aeradas. Engenh. Sanit., 27: 148-152.

Pereira Neto, J.T. 1994. Tratamento, reciclagem e impacto ambiental de dejetos agrícolas. In: Conferência sobre Agricultura e Meio Ambiente, 1., 1992, Viçosa. Anais... UFV-NEPEMA. Viçosa. p. 61-74.

Pereira Neto, J.T. 1996. Manual de compostagem. UNICEF. Belo Horizonte. $56 \mathrm{p}$.

Pereira Neto, J.T. 2007. Manual de compostagem: processo de baixo custo. UFV. Viçosa. $81 \mathrm{p}$.

Primavesi, A. 1981. O manejo ecológico do solo: agricultura em regiões tropicais. Nobel. São 


\section{COMPOSTAGEM DE RESÍDUOS ORGÂNICOS}

Paulo. 535 p.

Raiv, M.Y. Chen and Y. Imbar. 1986. Peat and peat substitutes as growth media for container grown plants. In: Chen, Y. The role of organic matter in modern agriculture. Martinus Nijhoff Publishers. Dordrecht. p. 227-287.

Ramjeawon, T.A. 2001. Modeling approach for determining the alkalinity requirement for the treatment of weakly buffered carbohydrate industrial wastewaters by the UASB process. In: World Congress Anaerobic Digestion, 9, 2001, Atuérpia. Proceedings ... Technological Institute. Atuérpia. 2: 571-574.

Reinhardt, T. 2002. Organic acids as a decisive limitation to process dynamics during composting of organic matter. In: Insam, H., N. Riddech, S. Klammer (Eds.). Microbiology of composting. Atuérpia: Springer-Verlag. Atuérpia. p. 177188.

Richard, T., N. Trautmann, M. Krasny, S. Fredenburg and C. Stuart. 2002. The science and engineering of composting. The Cornell composting website, Cornell University. http://www.compost.css.cornell. edu/composting_homepage.html. Acesso em: 12/08/2002.

Riffaldi, R., R. Levi-Minzi, A. Pera and M. de Bertoldi. 1986. Evaluation of compost maturity by means of chemical and microbial analyses. Waste Manage. Res., 4: 96-387.

Rivera-Rosario, R.A. 2003. Determinación de indicadores de maturez en la producción de composta. MMaestría en Agronomia. Universidad de Puerto Rico. Puerto Rico 127 p.

Rodrigues, M.S., F.C. da. Silva, L.P. Barreira e A. Kovacs. 2006. Compostagem: reciclagem de resíduos sólidos orgânicos. In: Spadotto, C.A.; Ribeiro, W. Gestão de Resíduos na agricultura e agroindústria. FEPAF. Botucatu. p. 63-94.

Roig, A., A. Lax, J. Cegarra, F. Costa and M.T. Jernandez. 1988. Cátions exchanger capacity as a parameter for measuring the humification degree of manure. Soil Sci., 146: 311-316.

Ruggieri, L. T. Gea, A. Artola and A. Sanchez. 2008. A study on air filled porosity evolution in sludge composting. Int. J. Environ. Waste Manage. http://www.sciencedirect.com Acessado em: 6/03/2009.

Said-Pullicino, D., F.G. Erriquens and G. Gigliotti. 2007. Changes in the chemical characteristics of water-extractable organic matter during composting and their influence on compost stability and maturity. Bioresource Technol., 98: 1822-1831.

Sanchez-Monedero, M.A., A. Roig, C. Paredes and P. Bernal. 2001. Nitrogen transformation by Rutgers system and its effects on $\mathrm{pH}$, EC and maturity of the composting mixtures. Bioresource Technol., 78: 301-308.

Seiffert, N.F. 2000. Planejamento da atividade avícola visando qualidade ambiental. In:Simpósio sobre Resíduos da Produção Avícola. Anais ... Concórdia. p. 1-20.

Sellami, F., R. Jarboui, K. Hachicha and E.A. Medhioub. 2008. Co-composting of oil exhausted olive-cake, poultry manure and industrial residues of agro-food activity for soil amendment. Bioresource Technol., 99: 1177-1188.

Sharma, V.K., M. Canditelli, F. Fortuna and C. Cornacchia. 1997. Processing of urban and agroindustrial residues by anaerobic composting: review. Energ. Convers. Manage., 38: 453-478.

Silva, M.S., L.A. Costa, M. Sestak, D. Olibone, A.V. Kaufmann, S.R. Rotta e R. Sestak. 2001. Monitoramento da temperatura em dois sistemas de compostagem (com e sem aeração forçada) de resíduos sólidos da indústria de desfibrilação de algodão com diferentes tipos de inóculo. In: Congresso Brasileiro de Engenharia Agrícola, 30, 2001, Foz do Iguaçu. Anais... Sociedade Brasileira de Engenharia Agrícola.Cascavel. CD ROM.

Silva, F.A. de M. 2005. Qualidade de compostos orgânicos produzidos com resíduos do processamento de plantas medicinais. Tese (Doutorado em Agronomia). Faculdade de Ciências Agronômicas. Campus Botucatu. Universidade Estadual Paulista "Julio de Mesquita Filho". Botucatu/SP. 92 p.

Sivakumar, K., V.R.S. Kumar, P.N.R. Jagatheesan, K. Viswanathan and D. Chandrasekaran. 2007. Seasonal variations in composting process of dead poultry bird. Bioresource Technol. http:/ /www.sciencedirect.com Acessado em: 28/ 01/2008.

Smith, J.L. and E.A. Paul. 1990. The significance of soil microbial biomass estimations. In: Bollog, J.M.; Stotzky, G. (Eds.). Soil, 6: 357-396.

Snell, J.R. 1991. Role of temperature in garbage composting. In: The biocycle guide to the art \& 


\section{VALENTE ETAL.}

science of composting. J.G. Press. Emmaus. p. 224-256.

Sundberg, C., S. Smars and H. Jönsson. 2004. Low $\mathrm{pH}$ as inhibiting factor in the transition from mesophilic to thermophilic phase in composting. Bioresource Technol., 95: 145-150.

Symanski, C.S. 2005.Caracterização de bactérias mesófilas presentes em processo de compostagem. Dissertação (Mestrado em Microbiologia Agrícola e do Ambiente). Faculdade de Agronomia. Universidade Federal do Rio Grande do Sul. Porto Alegre. $113 \mathrm{p}$.

Tang, J.C., T. Kanamori and Y. Inque. 2004. Changes in the microbial community structure during thermophilic composting of manure as detected by quinone profile method. Process Biochem., 39: 1999-2006.

Tardy, R.J. and R.W. Beck. 1996. Composting technology in the United States: research and pratice. In: The science of composting. part 1. Chapman \& Hall. England. p. 939-947.

Tsai, S.M., A.V.L. Baraibar e V.L.M. Romani. 1992. Efeito dos fatores do solo. In: Cardoso, E.J.B.N., S.M. Tsai, M.C.P, Neves (Eds.). Microbiologia do solo. Sociedade Brasileira de Ciência do Solo. Campinas. p. 60-72.

Tiquia, S.M., N.F.Y. Tam and I.J. Hodgkiss. 1996. Microbial activities during composting of spent pig manure sawdust litter at different moisture contents. Bioresource Technol., 55: 201-206.

Tiquia, S.M., N.F.Y. Tam and I.J. Hodgkiss. 1997. Effects of turning frequency on composting of spent pig-manure sawdust litter. Bioresource Technol., 62: 37-42.

Tiquia, S.M. and N.F.Y. Tam. 1998. Elimination of phytotoxicity during co-composting of spent pig-manure sawdust litter and pig sludge. Bioresource Technol., 65: 43-49.

Tiquia, S.M., N.F.Y. Tam and I.J. Hodgkiss. 1998a. Salmonella elimination during composting of spent pig litter. Bioresource Technol., 63: 193196.

Tiquia, S.M., N.F.Y. Tam and I.J. Hodgkiss. 1998b. Changes in chemical properties during composting of spent pig litter at different moisture contents. Agr. Ecosyst. Environ., 67: 79-89.

Tiquia, S.M. and Tam, N.F.Y. 2000. Co-composting of spent pig litter and sludge with forcedaeration. Bioresource Technol., 72: 1-7.

Tiquia, S.M. 2005. Microbiological parameters as indicators of compost maturity. J. Appl. Microbiol., 99: 816-828.

Tomati, U., E. Madejon and E. Galli. Evaluation of humic acid molecular weight as an index os compost stability. Compost Sci Util., 8: 108115.

Tomati, U, M. Belardinelli, M. Andreu and E. Galli. 2002. Evaluation of commercial compost quality. Waste Manage. Res., 20: 389-397.

Tuomela, M., M. Vikman and A. Hatakka. 2000. Biodegradation of lignin in a compost environment: a review. Bioresource Technol, 72: 169-183.

Turner, C. 2002. The thermal inactivation of E. coli in straw and pig manure. Bioresource Technol., 84: 57-61.

Valente, B.S. 2008. Tratamento de carcaças avícolas através da compostagem. Dissertação (Mestrado em Zootecnia). Faculdade de Agronomia Eliseu Maciel. Universidade Federal de Pelotas. Pelotas, $154 \mathrm{p}$.

Vergnoux, A., M. Guiliano, Y. Le Dréan, J. Kister,N. Dupuy and P. Doumenq. 2009. Monitoring of the evolution of na industrial compost and prediction of some compost properties by NIR spectroscopy. Sci. Total Environ. http:// www.sciencedirect.com. Acessado em: 12/ 03/2009.

Vespa, I.C.G. 2005. Características minerais e enegéticas do lixo urbano em processo de compostagem e biodigestão anaeróbia. Dissertação (Mestrado em Agronomia). Faculdade de Ciências Agronômicas Campus Botucatu. Universidade Estadual Paulista "Júlio de Mesquita Filho". Botucatu. 56 p.

Victoria, R.L., M.C. Piccolo e A.T. Vargas. 1992. O ciclo do nitrogênio. In: Cardoso, E.J.B.N., S.M. Tsai, M.C.P. Neves. Microbiologia do solo. Sociedade Brasileira de Ciência do Solo. Campinas. p. 105-119.

Vinneras, B. and H. Jonsson. 2002. Thermal composting of faecal matter as treatment and possible disinfection method - Laboratory scale and pilot-scale studies. Bioresource Technol., 84: 275-282.

Wetzel, R.G. 1983. Limnology. W.B. Saunders. Philadelphia. $400 \mathrm{p}$.

Zhang, Y. and Y. He. 2006. Co-compostig solid swine manure with pine sawdust as organic substrate. Bioresource Technol., 97: 20242031. 


\section{COMPOSTAGEM DE RESÍDUOS ORGÂNICOS}

Zucconi, F. and M. Bertoldi. 1986. Organic waste stabilization throughout composting and its compatibility with agricultural uses. In: Wise, D.L. Global bioconversions. CRC Press. Boca Raton. p. 109-137.

Zucconi, F. and M. Bertoldi. 1991. Specification for sold waste compost. In: The biocycle guide to the art \& science of composting. J.G. Press.
Emmaus. p. 200-205.

Zhu, N., C. Deng, Y. Xiong and H. Qian. 2004. Performance characteristics of three aeration systems in the swine manure composting. Bioresource Technol., 95: 319-326.

Zhu, N. 2007. Effect of low initial $\mathrm{C} / \mathrm{N}$ ratio on aerobic composting of swine manure with rice straw. Bioresource Technol., 98: 9-13. 